\title{
A New Approach for the Analysis of Deep Convective Events: Thunderstorm Intensity Index
}

\author{
Damjan Jelić $^{1, *(\mathbb{D})}$, Maja Telišman Prtenjak ${ }^{1}$, Barbara Malečić $^{1}{ }^{(0)}$, Andreina Belušić Vozila ${ }^{1}$, \\ Otília Anna Megyeri ${ }^{2}$ and Tanja Renko ${ }^{3}$ \\ 1 Department of Geophysics, Faculty of Science, University of Zagreb, 10000 Zagreb, Croatia; \\ telisman@gfz.hr (M.T.P.); bmalecic@gfz.hr (B.M.); andreina.belusic@gfz.hr (A.B.V.) \\ 2 Hungarian Meteorological Service, H-1024 Budapest, Hungary; megyeri.o@met.hu \\ 3 Croatian Meteorological and Hydrological Service, 10000 Zagreb, Croatia; tanja.renko@cirus.dhz.hr \\ * Correspondence: djelic@gfz.hr
}

Citation: Jelić, D.;

Telišman Prtenjak, M.; Malečić, B.;

Belušić Vozila, A.; Megyeri, O.A.;

Renko, T. A New Approach for the Analysis of Deep Convective Events: Thunderstorm Intensity Index. Atmosphere 2021, 12, 908. https:// doi.org/10.3390/atmos12070908

Academic Editor: Jimy Dudhia

Received: 11 June 2021

Accepted: 9 July 2021

Published: 14 July 2021

Publisher's Note: MDPI stays neutral with regard to jurisdictional claims in published maps and institutional affiliations.

Copyright: (C) 2021 by the authors. Licensee MDPI, Basel, Switzerland. This article is an open access article distributed under the terms and conditions of the Creative Commons Attribution (CC BY) license (https:/ / creativecommons.org/licenses/by/ $4.0 /)$.

\begin{abstract}
In this study, an investigation of a new thunderstorm intensity index (TSII) derived from lightning data is performed, along with its relationship to rain, wind, hail and waterspouts as well as instability indices (CAPE, LI, KI, and DLS). The study area is located in the northeastern Adriatic and includes various terrain types in a relatively small area (coastal, flatlands, hills and valleys, and mountain regions). The investigated period covers 11 years (2008-2018). The mathematical algorithm standing behind the TSII is based on the well-established methodology of lightning jump, allowing us to recognize areas where intensification in thunderstorms occurred. Our results suggest that these areas (with a positive TSII) experience significantly higher rain intensities and have higher total amounts of precipitation compared with areas where thunderstorms did not generate a TSII. Moreover, $76 \%$ of thunderstorm hail cases were associated with the presence of a TSII within a $15 \mathrm{~km}$ distance. The maximum reported wind speed also has higher values on a day with a TSII. Out of 27 waterspout events associated with lightning, 77\% were related to a TSII. Due to the good spatial $(3 \mathrm{~km} \times 3 \mathrm{~km})$ and high temporal $(2 \mathrm{~min})$ resolution of lightning data, the TSII can recognize even a local and short-lived intense system that is often misread by radars and satellites due to their inferior temporal resolution. The TSII is designed to be used as a climatological and diagnostic variable that could serve in lieu of more established data sources (e.g., station measurements and observations, radar imagery, etc.) if they are unavailable.
\end{abstract}

Keywords: northeastern Adriatic; precipitation; hail; wind gust; waterspout; CAPE

\section{Introduction}

Thunderstorms can produce severe weather, such as heavy rain, large hail, wind gusts, tornadoes, and cloud-to-ground lightning, which can cause significant amounts of damage and can endanger human lives [1]. Usually, these thunderstorms have large spatial and temporal scales, such as mesoscale convective systems (MCSs) or supercells. However, even local systems such as $\mathrm{Cb}$ families or single-cell $\mathrm{Cb}$ can produce some of these severe weather elements. Considering some well-established criteria for severe weather identification, it can be seen that they are relatively strict $[2,3]$, involving hail larger than $2 \mathrm{~cm}$, wind gusts above $25 \mathrm{~m} / \mathrm{s}$ and flash floods. In agricultural terms, a dense hail with diameters $<10 \mathrm{~mm}$ in the blooming season or just before harvest can produce significant amounts of damage [4]. Additionally, it can indirectly endanger human life, causing traffic accidents. Heavy rain does not need to be large in total quantity to cause harm if the local intensity is high and it can thus temporarily flood the area $[5,6]$. Wind gusts pose elevated risks to structures, trees and any outdoor activities, and their reach is several tens of kilometers ahead of the storm [7,8]. Even a moderate gust can shake down various fruits during the harvest season or produce damage to trees and vines if the soil is soaked and soft from rain, and the roots are shallow, as reported by farmers and wine 
producers in the northeastern Adriatic region during our field measurements of hail. With this in mind, any thunderstorm system exhibiting intense precipitation, hail, wind gusts or producing a tornado should be considered potentially hazardous.

Tornadoes, in this study mostly observed over water (waterspouts), can pose a threat, especially if they move onshore. Winds connected to tornadoes usually exceed $29 \mathrm{~m} / \mathrm{s}$ [9], and although most reported waterspouts in the Adriatic region are considered non-mesocyclonic, more than half of them are thunderstorm related [10]. Therefore, they are considered dangerous, especially for maritime and tourist activities, which are of significant importance for the region of interest. Active monitoring of these thunderstorm systems can be accomplished using remote sensors, such as radars, satellites and a lightning detection network. Nevertheless, it is difficult to obtain good radar coverage in most regions due to the limited range and various sampling frequencies of radars, as well as their overall cost [11]. Additionally, the frequency of satellite imaging is still relatively low to capture short-lived systems [12]; thus, lightning measurements are the only data source that has large spatial coverage and sufficiently high temporal resolution (1 s). Many convective storms are accompanied by lightning strikes, which are the main feature of storms over land [13]. The number of lightning strikes per storm generally depends on the concentrations of ice crystals and graupel and on the updraft intensity. When the updraft is sufficiently strong and a cloud contains both ice crystals and graupel, the non-inductive charging mechanism is triggered, and electrification (i.e., production of lightning strikes) will occur [14-16]. Depending on the strength of the updraft, lightning activity can increase or decrease, providing us with information on the development and intensity of a system.

There is a long history of thunderstorm studies using various data sources and methods. A comprehensive review of the methods is provided by Hayward et al. [17]. With respect to climatological studies, the most commonly used methods are thunderstorm frequency, thunderstorm tracking and flash density. Any of the above methods can provide information about spatial and temporal differences in lightning activity in a particular region, as well as providing spatial and temporal trends on various time scales. Thunderstorm frequency (per certain area and period) is a good measure for the overall impression of interannual, annual, seasonal and/or diurnal variabilities of thunderstorms over a particular region and is most commonly obtained from station observations. By using remote sensing detection of lightning (satellite, radar, and lightning detection networks), thunderstorm tracking and flash density can be obtained. Thunderstorm tracking can provide useful information on preferred thunderstorm movement over a specific region, providing data regarding the mesoscale or synoptic driver or time period, as well as information on the lifecycle, speed and intensity development of a particular thunderstorm. Flash density (per square kilometer and certain period) is in nature similar to thunderstorm frequency since the occurrence of lightning confirms the presence of thunderstorms. By using flash density, one can differentiate between different types of flashes (cloud to ground, cloud to cloud, or positive or negative flashes), providing more detailed inspection of thunderstorm behavior suited for different purposes, e.g., ground flash density as a measure of the risk to the asset. Additionally, by observing flash density at very short time scales (a few minutes), one can obtain detailed dynamic properties of thunderstorms and can attempt to associate them with severe ground effects. In the past decade, a new Lagrangian approach has been developed to connect lightning data with hail occurrence, severe winds, and tornadoes. The method is based on a mathematical model that detects sudden increases in flash density within a selected thunderstorm known as a lightning jump [18-20]. To date, the lightning jump method has been used in nowcasting as a precursor of severe weather, as the jump occurs several minutes to generally one hour prior to a severe event [19-25]. In nowcasting, the focus is on the detection of the first lightning jump; therefore, the forecaster would gain as much lead time as possible. Although the storm usually produces multiple jumps during the life cycle [17], later jumps do not offer as much of a lead time and are considered less relevant [24]. Although very powerful, the lightning jump method still does not provide information about the location of the severe effects. If we consider all the 
above methods, they also lack that skill. Thunderstorm footprints, which can be obtained from flash density, are spatially too large to adequately represent locations of severe effects, if any are present at all. If any threshold is applied to cut off areas with low flash density, there is a chance one will exclude a significant number of low lightning thunderstorms bearing severe effects. In other words, flash density is a measure of lightning activity relative to the storm rather than severe effects, and to obtain information about severe weather through lightning activity, a measure invariant to the total number of flashes is needed. The lightning jump method is invariant to the total number of flashes and depends only on the relative change in lightning dynamics, but location accuracy is exchanged in favor of gaining more lead time. Additionally, the lightning jump method involves some type of storm tracking using radar or lightning clustering to determine storm trajectory for nowcasting purposes [25] and/or to define storm clusters from within which the lightning data are obtained [20]. Exploiting the lightning jump method and converting it from a Lagrangian to Eulerian standpoint, we obtain a new angle for thunderstorm analysis and introduce a new thunderstorm intensity index (TSII). In our approach, radar information is excluded from the equation, and therefore, the method can be applied at the same scales as those of lightning networks. Furthermore, through the TSII, a spatial footprint of a thunderstorm can be obtained, suggesting the most intense area of the storm in terms of lightning dynamics regardless of thunderstorm size. In this way, we will finally be able to address both spatial and temporal relationships between lightning and severe effects.

Through this paper, we will focus on the spatial relationship between potentially severe effects and the TSII index, since this is the link that is currently missing. In addition, this study will continue previous research on lightning [26] and hail [27], revealing new knowledge about deep convective activity over the northeastern Adriatic region.

To achieve the aforementioned goals, we will first address all data sources used in this study in Section 2. In Section 3, the Results section, we will elaborate, in detail, the derivation of the TSII, and the methods used through verification. Also, we will verify the capabilities of TSII against all available data sources. Additionally, we will present a brief climatology of the TSII and related synoptic drivers. Finally, in Section 4, we will provide some conclusions and remarks.

\section{Data and Methods}

In this paper, we use four different data sources. The first and most important data source is total lighting measurements from the Lightning Detection Network in Europe (LINET), from which the TSII is calculated [28]. Afterwards, we compare them against the remaining data sources. The second data source comes from the Croatian Meteorological and Hydrological Service and addresses precipitation and wind measurements and hail observations. The third data source comes from public reporting of waterspouts, while the fourth is the ECMWF reanalysis ERA5 with a horizontal resolution of $0.25^{\circ}$ [29]. In the following subsections, we will address each of the data sets in more detail. All above data sources are available for the northeastern Adriatic region presented in Figure 1. The choice of the domain was motivated by previous studies that showed high lightning activity [26], increased presence of overshooting tops [30], and high frequencies of hail as well as highly complex terrain [27]. 

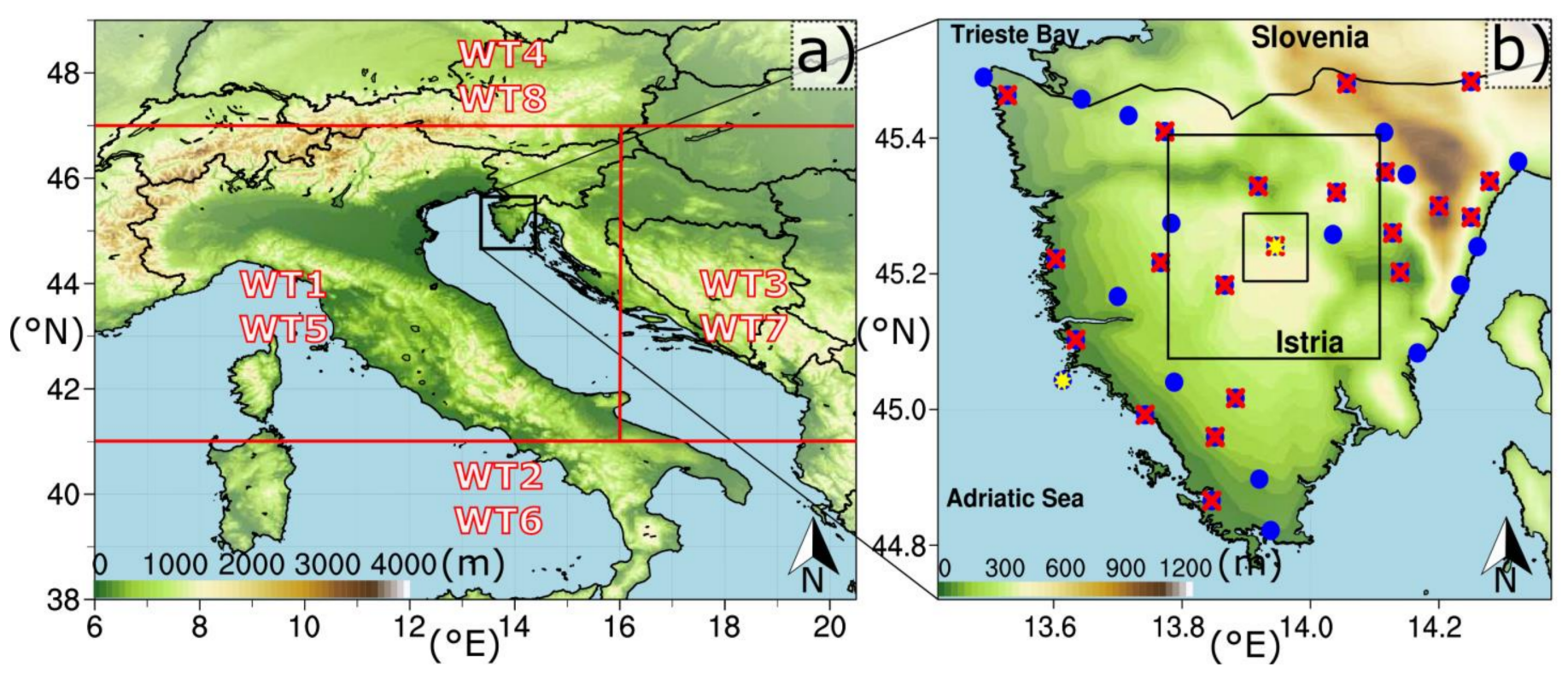

Figure 1. (a) The central Mediterranean region investigated in this paper. The area is covered by lightning data from the LINET network in the 2008-2018 period, and it was a base for weather type classification. Color bar shading indicates elevation (m). Red lines indicate 4 influencing sectors related to synoptic weather types, as indicated in each sector. (b) The northeastern Adriatic region. Blue dots represent precipitation stations, while red crosses denote hail-reporting stations. The two automated stations are represented with yellow stars. Nested black squares indicate two areas of influence used in this study ( $3 \mathrm{~km}$ around the station for the inner and $15 \mathrm{~km}$ for the outer nested squares).

\subsection{Lightning Data}

For the purpose of this study, we used LINET lightning data from January 2008 to December 2018. The LINET system is based on approximately 130 sensors that have been installed in many European countries (e.g., [28]). This system uses a very low and low frequency range (VNF/NF) and detects the density of the magnetic flow during atmospheric discharge by means of two mutually perpendicularly placed annular antennas [31-33]. All LINET system sensors are of the same type, which ensures the homogeneity of the collected data and eliminates the occurrence of an error that would occur due to the use of different parameters, measurement principles and the method applied if different types of sensors would be used. To determine the accuracy of the lightning location, the TOA ("Time of Arrival") method is employed, which requires installation of a larger number of sensors.

Along the Croatian territory, the network consists of six sensors [26], that are accompanied by a number of sensors in neighboring countries. The location of sensors that are up to $250 \mathrm{~km}$ away gives a detection efficiency greater than $90 \%$ over Croatia [31]. The LINET reports provide lightning strike locations of larger and smaller amplitudes. Larger amplitude currents usually originate from cloud-to-ground discharges, while smaller amplitudes are due to discharges between clouds or within clouds. In the LINET system, the effective time accuracy of a strike over Croatia is $\sim 0.2 \mathrm{~ms}$. In the period from 2009 to 2018, the median values of detected current amplitude values had doubly decreased [32,33], showing significant improvement in the sensitivity detection toward smaller stroke current amplitudes. Strokes with small amplitudes occur very often, and consequently, the increased sensitivity of the detection amplitudes enhanced the total number of detected lightning strokes since 2016 [32]. The average minimum detectable signal is $0.7 \mathrm{kA}$ for the total investigated domain (in Figure 1a), and the median location accuracy error is $\pm 84 \mathrm{~m}$. This statistical location accuracy error results from mathematical rules, system technology and performances of the mathematical algorithm used in the system. Despite certain errors in measurements regarding the location accuracy, minimum detectable signal and the ability to detect subsequent (usually negative) strokes, none of the potential issues significantly affect our computation and conclusions. The reason for this is that our method 
deals with total lightning without a separation between types or polarities of lightning strikes at a raster of $3 \mathrm{~km} \times 3 \mathrm{~km}$.

Using total lightning, we developed a 2D database of lightning strikes at a $3 \mathrm{~km} \times 3 \mathrm{~km}$ resolution and $2 \mathrm{~min}$ intervals for the entire period. Higher temporal and spatial resolutions are possible; however, they exceed our computational and storage resources. The resolution used here is still much better than the available satellite and radar measurements for this area and sufficiently high to discern some local characteristics of thunderstorms and their impacts at the local scale. We will employ this dataset to develop the TSII and as a reference to differentiate between thunderstorm days with and without the TSII.

\subsection{Precipitation}

During the observed period (2008-2018), the northeastern Adriatic region had 37 weather stations from the Croatian Meteorological and Hydrological Service, which included $24 \mathrm{~h}$ sums of precipitation starting at $07 \mathrm{CET}(\mathrm{CET}=\mathrm{UTC}+1)$. The stations are presented with blue dots in Figure $1 \mathrm{~b}$, and these data are considered to be the main source for our validation. There were 17532 precipitation records in the observed period. In addition, we used one automated station to obtain 1 min daily maxima of precipitation intensity. This station is located on a lighthouse on a small island (approximately $3500 \mathrm{~m}^{2}$ ) named "Sv. Ivan na pučini", approximately $3 \mathrm{~km}$ from the peninsula (yellow star on the coast in Figure 1b). It is the most distant island of the local archipelago unshielded by other larger islands. This automated station worked in total from 2009 to 2018 with occasional interruptions. Regardless, we were able to obtain 2633 operating days, of which 881 were precipitation days. For future reference, we will address this station as a coastal station. Due to the nature of our work and simplicity, we define a day with precipitation as a day reporting precipitation without any threshold.

\subsection{Wind}

Another set of measurements are data from automated cup anemometers located in the aforementioned coastal station and one located in the center of the Istrian Peninsula in Pazin (yellow star in Figure 1b). For future reference, we will address this station as an inland station. Due to local topography, the inland station is relatively shielded. We were able to obtain $10 \mathrm{~min}$ wind averages for each day, and we used maximum daily value to approximate the strongest gust measured on a particular day. Although the $10 \mathrm{~min}$ interval is relatively long to capture peak values, it is still sufficient to indicate the presence of a strong wind. The coastal station was operational from September 2009 to the end of 2018 with sporadic interruptions; thus, we obtained 3060 operating days. The inland station operated during the entire period, and despite sporadic interruptions, we collected 3896 operating days.

\subsection{Hail}

The database of hail includes data from 2008 to 2017. Hail records were observed and written down in weather diaries from where they were extracted and digitalized by Jelić et al. [27]. To ensure the maximal number of hail records, we considered all hail sizes with minimum hailstones sizes larger than $5 \mathrm{~mm}$. In this way, we were able to obtain 269 hail records from 21 selected stations marked with a red cross in Figure $1 b$.

\subsection{Waterspouts}

Based on several different sources (weather stations, mass media, local residents and meteorology enthusiasts, as well as a survey that was active since 2011) [10], 53 independent reports of waterspouts were collected over 42 days during the observed period. All reports consist of date and location, most of them also have time of occurrence and duration of the event, and 23 reports included information on the number of waterspouts and/or accompanying meteorological phenomena (rain, thunderstorm, lightning, etc.). Although validation of all reports (mostly by confirmation with photos or several sources of the same 
occurrence) was made to avoid errors in further analysis, questions can still arise regarding the quality of these data, especially those observed during the night.

\subsection{ERA5 Reanalysis}

We computed instability indices, deep layer shear and objectively derived weather type (WT) analysis for the observed period using ERA5 data. For instability indices and kinematic parameters, we used (i) daily mean fields (as shown in [27]) of the most unstable CAPE (MUCAPE) by lifting the parcel with the maximum equivalent potential temperature values in the lowest $400 \mathrm{hPa}$, (ii) K-index (KI) from the temperature difference between 850 and $500 \mathrm{hPa}$ and the moisture content of the lower atmosphere, (iii) lifted index (LI) as a difference between the observed temperature and the temperature of an air parcel at $500 \mathrm{hPa}$, (iv) the temperature of an air parcel lifted moist adiabatically to $500 \mathrm{hPa}$ from the surface and (v) deep layer shear (DLS) as the difference in wind speed between the surface $(10 \mathrm{~m})$ and $6 \mathrm{~km}$. All of the above variables were computed using the Sounding and Hodograph Analysis and Research Program in Python (SHARPpy) [34].

Objectively derived WTs are composed of 17 different weather patterns, of which 8 correspond to cyclones, another 8 correspond to anticyclones, and one pattern represents a quasi-non-gradient field where the mean $\nabla p$ is less than $0.06 \mathrm{hPa} / \mathrm{km}[27,35]$. We divided synoptic systems into four regions taking into account the geographic position of the system affecting our domain and taking into account the location of the center of the synoptic system (red lines in Figure 1a): the front of the synoptic system affecting the domain (WT1 and WT5), the upper part of the system affecting the domain (WT2 and WT6), the back of the system affecting the domain (WT3 and WT7), and the lower part of the synoptic system affecting the domain (WT4 and WT8). Additionally, for each of the WTs, we differentiate between deep and shallow systems.

\subsection{Thunderstorm Intensity Index (TSII)}

The aim of this paper is to present and validate a new index for thunderstorm intensity, mathematically based on the method used to detect lightning jumps. The previous method uses a set of mathematical operations that measure lightning behavior in shorter time intervals (1-5 $\mathrm{min}$ ) over several steps. While different iterations of this method have been developed $[18,19]$, the guiding principle is the same. Prior to any computation, one usually defines the storm center using some type of storm-tracking algorithm. Furthermore, an area of influence within which lightning strikes are collected in each timestep is defined. The final steps include: (i) computation of the trend in the number of lightning flashes between several consecutive time steps, (ii) calculation of the standard deviation of several consecutive trends, (iii) the trend(s) is(are) compared against the standard deviation from the previous step and (iv) iteration of the procedure by moving one step forward. Finally, when a trend exceeds a predefined threshold of the standard deviation (the most common threshold is two sigmas), it is considered that a lightning jump occurred.

Although mathematically the same, the key difference between lightning jumps and the TSII is in lightning data retrieval. Contrary to lightning jump data retrieval, the TSII does not require the use of a storm tracking algorithm and influence radius because it observes a storm passing over a predefined grid on the ground, and therefore, this approach offers a new angle. The storm is divided into arbitrarily small segments (i.e., a predefined grid), allowing us to identify the potential impacts of the storm on a particular grid point and at a particular point in time. Since the TSII algorithm is computed independently for each grid point, severe storms will leave a trail of the TSII, revealing the area over which the most active part of the storm has passed. In other words, the TSII is a diagnostic tool that, in retrospect, highlights areas over which a storm was the most active. Additionally, due to the current computational settings, the TSII is a binary (yes/no) index that obtains a positive value (e.g., TSII $=1$ ) if the storm intensifies rapidly, while otherwise TSII equals to zero. 
To illustrate the computational process of the TSII, we selected one thunderstorm case (Figure 2a) from our database. On 11 May 2018, local convection was able to organize into a severe thunderstorm in the northeastern Adriatic, producing flash floods, hail and strong winds. The thunderstorm lasted approximately $90 \mathrm{~min}$ in total. Through media reports (magenta star), very dense hail was reported in two regions (black triangles), followed by flash floods at both locations. The northern location also reported strong winds. From station measurements (circles), the maximum accumulated rain was $55 \mathrm{~mm}$. Additionally, four hail pads (black triangles) measured small dense hail with maximum diameters of $11.6 \mathrm{~mm}$ and a maximum of 2800 hailstones $/ \mathrm{m}^{2}$. In Figure $2 \mathrm{~b}$, a graphical computation process of the TSII based on one selected grid point from Figure $2 \mathrm{a}$ is shown. To obtain the lightning data, we divided our domain into a $3 \mathrm{~km} \times 3 \mathrm{~km}$ grid and summed all lightning flashes located in a particular grid. The choice of grid size and time interval ( $2 \mathrm{~min}$ ) was a balance between computation speed and data storage requirements. Based on this compromise and following Figure $2 b$, the average flash rate per minute at $2 \mathrm{~min}$ intervals was computed:

$$
F R_{a v g}(t i)=\frac{F R(t i)}{2}
$$

where $F R_{\text {avg }}$ is measured in flashes per minute (blue curve in Figure $2 \mathrm{~b}$ ), and then a weighted moving average is applied to obtain the red curve:

$$
M F R_{a v g}(t i+3)=\frac{1}{3}\left[F R_{a v g}(t i+3)-\frac{2}{3} F R_{a v g}(t i+2)-\frac{1}{3} F R_{a v g}(t i+1)\right]
$$

and computed consecutive trends for all time periods of the observed period per grid point (black curve):

$$
\frac{d}{d t} M F R_{a v g}(t i+4)=\frac{M F R_{a v g}(t i+4)-M F R_{a v g}(t i+3)}{(t i+4)-(t i+3)}=D F R D T
$$

The standard deviation $(\sigma)$ of trends (DFRDT) was computed for each of the five consecutive time steps and multiplied by 2 (green curve in Figure 2b). To obtain a TSII, the sixth consecutive trends must be higher than $2 * \sigma$ obtained from the previous five trends (indicated with an arrow pointing from the TSII). The lightning characteristics of convective cells alongside hailstorm tracks show that the local mean lightning density close to a hail event exceeded 1.25 strikes per $1 \mathrm{~km}^{2}$ over $5 \min$ [23]. Converted to our resolution of $3 \mathrm{~km} \times 3 \mathrm{~km}$ and $2 \mathrm{~min}$ interval, the minimum threshold for a TSII should be 4.5 strikes over $2 \mathrm{~min}$. Therefore, to ensure the physical meaning of TSII occurrences, we ignore all TSII arising from fewer than 5 strikes at any point over a 2 min interval (magenta line in Figure 2b). By repeating the method for each of the grid points in Figure 2a, the TSII footprint (yellow boxes) and the thunderstorm footprint (light blue) were provided. It should be noted that one storm event can produce multiple TSIIs depending on its size and intensity, as seen in our example. Some preliminary studies have suggested that there is added value for hail if we consider areas with multiple TSIIs; however, in this study, we will focus on the full TSII footprint to grasp the general capabilities and benefits of the described approach. 


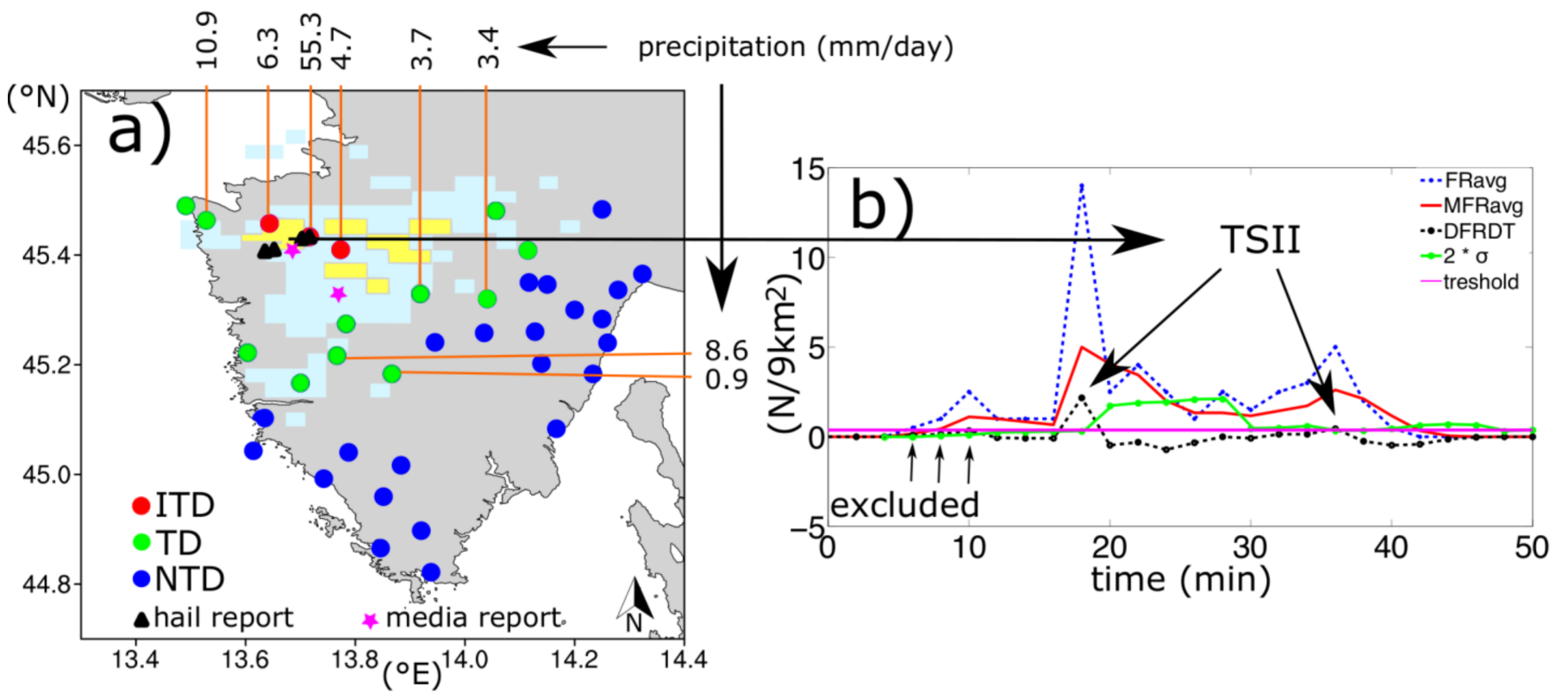

Figure 2. Real example of the TSII calculation based on the case from 11 May 2018 recorded over the northeastern Adriatic. In (a), a thunderstorm footprint is illustrated in light blue, while the TSII footprint is illustrated in yellow. Circles show location of precipitation stations. Different circle colors highlight three different environments that a station can be affected by. Red indicates an intense thunderstorm environment (ITD), green indicates a regular thunderstorm environment (TD), and blue indicates a non-thunderstorm environment (NTD). Four black triangles show hail records reported from the hail pad network located in the region. Magenta stars indicate media reports of extreme weather (hail, flash floods and severe winds). Orange lines connect stations with precipitation amounts recorded during the observed day. In (b), a time evolution of the average flash rate (in blue) is further processed by equations (2) (red line) and (3) to obtain DFRDT (black dash-dot line). Points exceeding the green line $(2 \sigma)$ and appearing above the threshold (magenta line) are considered TSII $=1$.

To understand and validate the capabilities of the TSII, various data sources addressed above have been used, and their relationship was examined. In the process of development of the TSII database for an observed period of 11 years, we were able to store hourly sums of the TSII. Furthermore, to maintain simplicity while aligning with the main data source $(24 \mathrm{~h}$ precipitation records) and avoiding potential uncertainties with the timestamp accuracy of particular data records, daily data were used as a working frame. Due to validation and numerical comparison, all available data sources were georeferenced with respect to the grid, i.e., each station obtained a $3 \mathrm{~km} \times 3 \mathrm{~km}$ grid point best corresponding to its geographic coordinates. Since waterspouts had a descriptive location (usually a nearby town or village on the shore) instead of coordinates, we examined each case separately using a subjective approach.

\subsection{Verification Approach}

Depending on the variable, two areas of influence were used around the location to verify its relationship to TSII and lightning, as illustrated with black nested squares in Figure $1 \mathrm{~b}$. The inner square indicates a $3 \mathrm{~km}$ area of influence used for precipitation, and the larger square is selected as a $15 \mathrm{~km}$ area of influence for wind, hail and waterspouts data.

By using the area of influence, three potential environments that can affect the station data were defined. The aim is to see if the area where the TSII footprint is located provides additional information about the thunderstorm. Three environments are defined as follows:

(1) Non-thunderstorm environment (NTD): if no lightning or TSII footprint was detected within a predefined area of influence;

(2) Thunderstorm only environment (TD): if only the lightning footprint was detected within a predefined area of influence; 
(3) Intense thunderstorm environment (ITD): if the TSII footprint is detected within a predefined area of influence.

A realistic display of the described environments is shown in Figure 2a, where we highlighted the TSII and lightning footprint with yellow and light blue boxes, respectively. Different colors of circles indicate which environment was assigned to a particular station. In total, the applied definition gave three stations with an ITD environment (red circles), 11 stations with a TD environment (green circles), and 23 stations with an NTD environment (blue circles). Furthermore, for precipitation data, after we assigned environments, an additional filter was created to eliminate those stations that reported no precipitation. In this particular case, all NTD stations had $0 \mathrm{~mm}$ precipitation; however, if a mixed convective/stratiform event occurred, a considerable amount of NTD could be obtained. Additionally, the 10th, 25th, 50th, 75th and 90th percentiles of a particular variable and particular environment were calculated to inspect differences between them.

\section{Results and Discussion}

\subsection{Verification of the TSII}

The potential of the TSII was analyzed using data of precipitation, maximum wind speed, hail and waterspouts. The relationship of the TSII to instability indices and DLS computed from ERA5 reanalysis data was further examined. Special attention is given to the potential application of the TSII in local convective events.

\subsubsection{Precipitation}

The first step is to inspect how the occurrence of the TSII is related to intense precipitation events using data from the automated station (yellow star on the coast in Figure 1b). In the observed period, the automated rain gauge station had 2633 operating days, of which 881 days were with rain and 202 days were related to thunderstorms. From these thunderstorm days, 72 days included the presence of an ITD footprint in the immediate vicinity of the station. Figure 3a displays box and whisker plots of daily maximum $1 \mathrm{~min}$ precipitation intensity for NTD environments (in blue), TD environments (in green), and ITD environments (in red). The results show that during the NTD, overall precipitation intensities were low, with a median value of $0.06 \mathrm{~mm} / \mathrm{min}$. During the TD, precipitation intensity was higher with a median value of $0.18 \mathrm{~mm} / \mathrm{min}$, and for the ITD, rain intensities were the highest, exhibiting a median value of $0.51 \mathrm{~mm} / \mathrm{min}$. Thus, environments including the TSII obtained significantly higher values of precipitation intensity compared with both the NTD and TD. These results are consistent with those from Gaál et al. [5], who presented threshold peak intensities for four precipitation stations in Switzerland. The results obtained suggest that the TSII indeed highlights areas in thunderstorms with high intensity precipitation.

Furthermore, $24 \mathrm{~h}$ accumulated precipitation over the automated station was examined. Although the precipitation data present a combined contribution from both stratiform and convective precipitation, our results in Figure $3 \mathrm{~b}$ show a clear difference among particular environments, with the TSII having the highest values. To confirm the obtained results, we used 37 precipitation stations that reported daily total rain rates and repeated the method for each of them. In summary, over the period of 11 years, there were 17,532 rain records, out of which 4179 included thunderstorm footprints and 1149 included TSII footprints. From these, $31 \%$ of rain events were associated with thunderstorms, while $9 \%$ contained intense thunderstorms due to positive TSII values. On average, $27 \%$ of thunderstorms exhibited rapid intensification near the precipitation station, resulting in more pronounced rainfall rates, as confirmed in Figure 3c. 

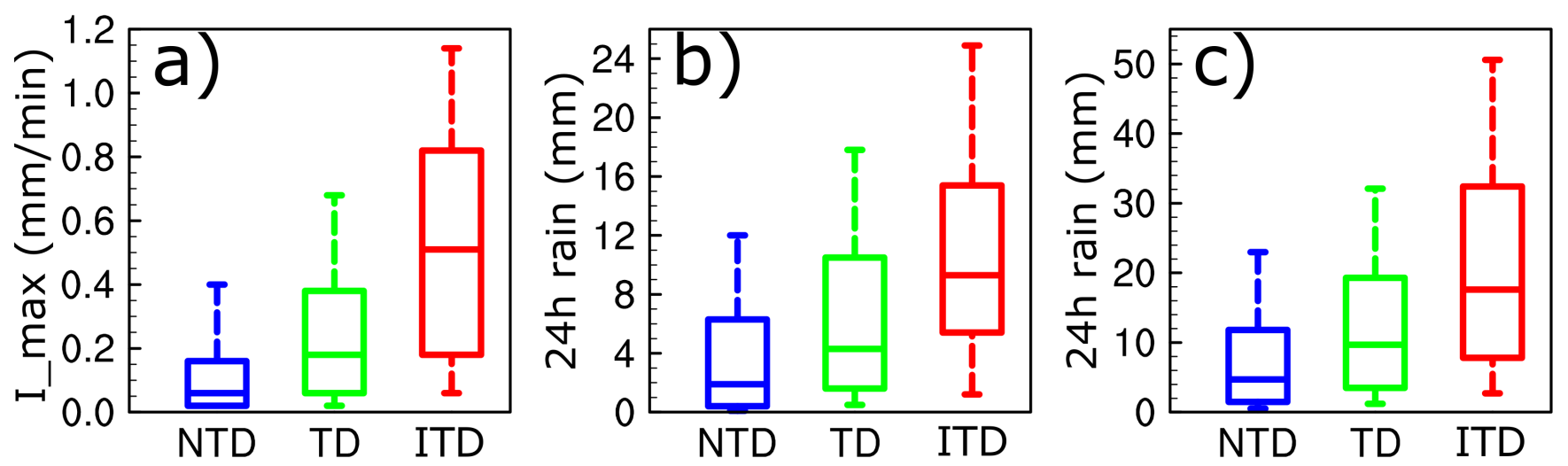

Figure 3. Box and whisker plot comparisons of the (a) precipitation intensity derived from 1-min daily maximum intensities for the automated precipitation station located on the coast, (b) total daily precipitation for the same station and (c) total daily precipitation based on 37 precipitation stations located in the northeastern Adriatic region. The median values are shown with the horizontal lines in the boxes; box edges are the 25th and 75th percentiles, and the whiskers represent the 10th and 90th percentiles. The blue box and whisker are related to the NTD, green to the TD and red to the ITD environments.

In general, the overlap between values of different environments is expected, especially between the TD and ITD, for several reasons. First, the method is designed to be sufficiently robust to allow us to observe relationships with all severe effects. Therefore, tailoring of the method should be performed for specific severe effects. Second, our method considers all precipitation events regardless of type, size and intensity, and thus, it is expected that a very large system produces higher precipitation intensities and higher total amounts in a larger area and finally contributes more to the TD. Third, georeferencing of stations to a $3 \mathrm{~km}$ grid can sometimes place stations into a corner of a pixel, and by introducing an additional $3 \mathrm{~km}$ area of influence, in some cases, can place stations farther away from a particular environment, causing smaller (than expected) values to be recorded. The consequence is the most evident in lower values of the ITD. Fourth, during one day, stratiform precipitation can be superposed on both TD- and ITD-affected stations. Statistically, there are three times more TD environments compared with ITD environments, indicating that the contribution of stratiform precipitation is more pronounced at higher values of TD environments. Fifth, for short-lived and small systems, the footprint of intense precipitation can be smaller than $3 \mathrm{~km}$ in width and can easily miss the station(s). Finally, due to complex topography, local hills can slightly influence thunderstorm trajectories and indirectly shield stations from more severe impacts. Regardless, median values show clear differences between selected environments and suggest that the TSII footprint contains more intense precipitation compared with other environments, providing additional information about observed thunderstorms.

\subsubsection{0-m Wind}

Wind gusts and microbursts are also one of the consequences of thunderstorms. While microbursts are very hard to capture due to their highly localized nature, wind gusts and gust fronts tend to reach $50 \mathrm{~km}$ from the storm center [8]. For comparison, only thunderstorms and TSII events that occurred in the relative vicinity of a station, i.e., $15 \mathrm{~km}$ from the station, were considered. Since our domain is relatively small and we are not able to determine in which direction a particular storm has traveled, including larger areas would be beneficial for some events. However, the number of false events would also increase significantly. Analyzing wind speeds from two locations (coastal (Figure 4a) and inland (Figure 4b)), a significant difference in the overall maximum wind speeds was found, which was expected due to geographic differences. However, it is clear that for the TD environments, higher wind speed maxima were measured compared to the NTD environments, and for the ITD environments, the highest median maximum wind speeds were recorded. For further investigation, the 90th percentile for the entire period and each 
station considered was calculated to isolate very strong winds for both stations. The 90th percentile for the coastal station was $17.0 \mathrm{~m} / \mathrm{s}$, while that for the inland station was 12.8 $\mathrm{m} / \mathrm{s}$. Within that upper range, $6 \%$ of the strongest wind observations at the coastal station occurred in NTD environments, while 19\% and 35\% occurred in TD and ITD environments, respectively. For the inland station, the distribution of very strong winds was $8 \%$ NTD, $15 \%$ TD, and 25\% ITD.
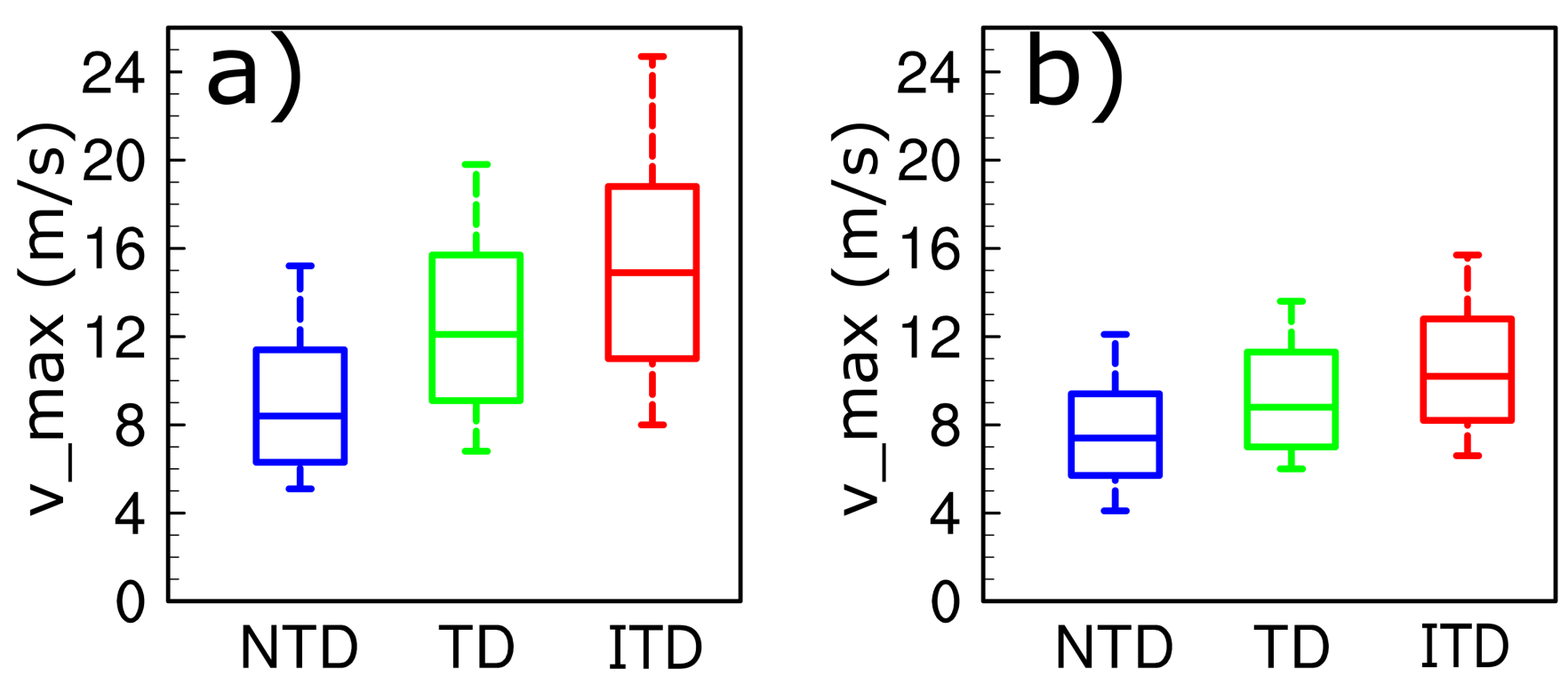

Figure 4. Same as Figure 3 but for daily $10 \mathrm{~min}$ maximum wind speed (m/s) for the (a) coastal station and (b) inland station.

In addition, wind roses for very strong winds in Figure 5 show frequency and mean wind maxima for selected directions $\left(+/-11.25^{\circ}\right)$. The first row $(\mathrm{a}-\mathrm{c})$ indicates the inland station while the second row $(\mathrm{d}-\mathrm{f})$ indicates the coastal station. The columns indicate NTD, TD and ITD environments. Columns 1 (NTD) and 2 (TD) show dominant winds from the first and second quadrants, which are well-known directions for bora (mostly NE-E) [36,37], and sirocco winds (mostly SE-S) [38]. The bora is a gusty offshore wind that brings dry and cold air over the coastal region, while sirocco is a warm, humid wind often followed by convection. Both types of air flow can be associated with severe wind speeds; however, only sirocco can be seen within the TD and ITD environments. For ITD environments, other wind directions became evident. For the coastal station, the most frequently reported wind directions were from the SW to NW, suggesting that storms form over the sea and travel inland. Winds from the NE to E can be partially explained by convective drift from the inland region to the coast [27]. For the inland station, the most dominant wind is from the SE direction (sirocco), while NE-E has the smallest contribution (16\%). These results are expected due to the distribution of the local hills and mountains partially shielding Pazin from thunderstorm gusts. Although a positive relationship between the TSII footprint and wind gusts is identified, the overall intensities and relative frequencies suggest that the inland region is rarely affected by severe winds, while the coastal region does experience severe gusts related to both TD and ITD environments.

The importance of southerly wind directions for the occurrence of heavy precipitation on the eastern side of the Alps is highlighted in Ivančan-Picek et al. [39]. Based on the wind fields simulated with the ALADIN/LACE model, it was determined that the analyzed heavy precipitation event was caused by a frontal modification that was influenced by surface convergence between the warm southerly wind and the colder northeasterly bora wind. Moreover, Toreti et al. [40] investigated the relationship between precipitation extremes in the Mediterranean region and associated upper-level synoptic-scale flow structures. It was shown that during extreme precipitation events in the western Balkan Peninsula, a broad potential vorticity trough is located over central Europe. The western 
Balkan Peninsula is then affected by the eastern flank of the trough and is under the influence of strong SW winds at $850 \mathrm{hPa}$. The potential for an interaction between SW winds and NW-SE oriented orography in this area is indicated as well.
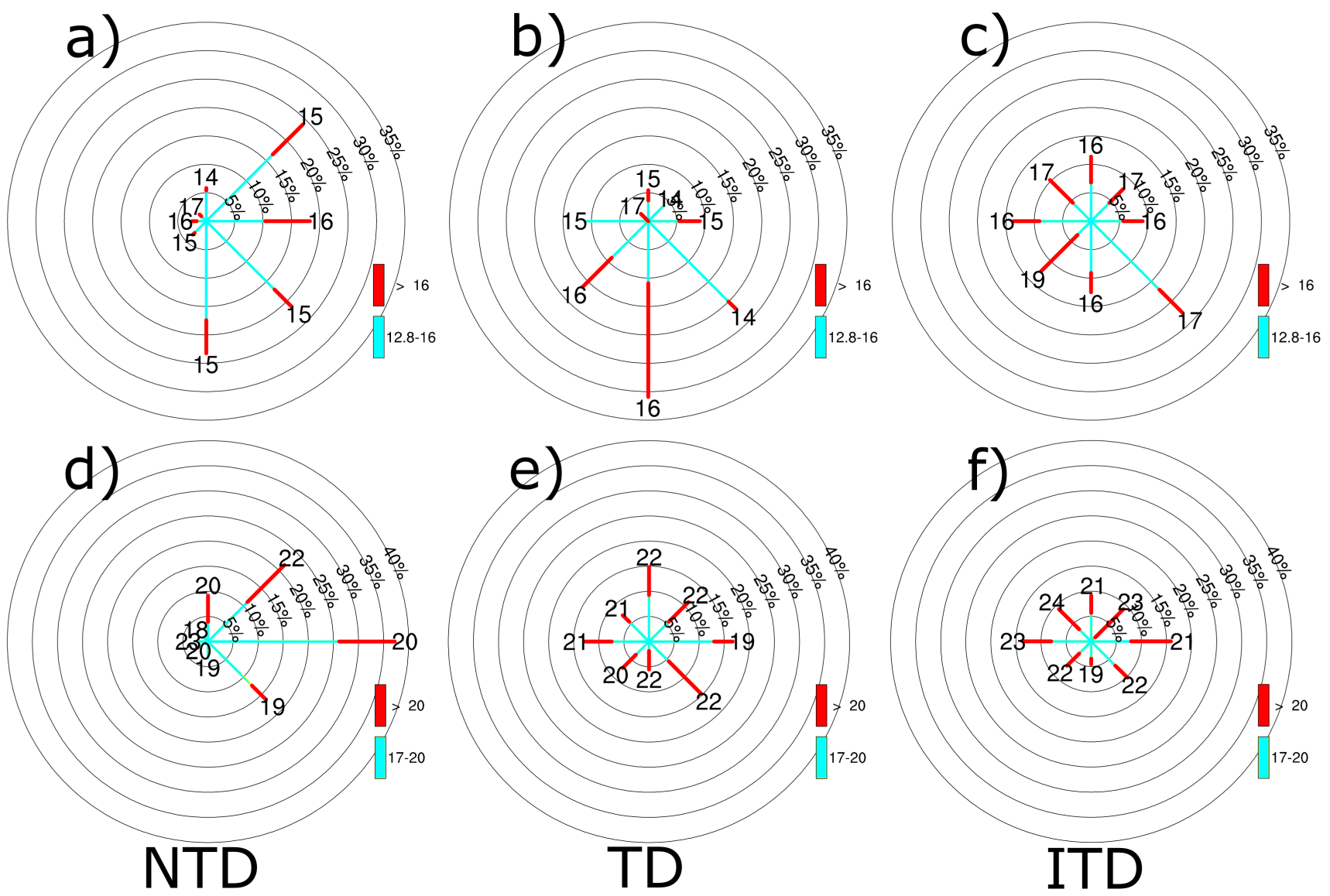

Figure 5. Wind roses (in m/s) plotted from the 90th percentile of 10 min maximum winds for inland (Pazin, (a-c)) station and coastal (Sv. Ivan na pučini, (d-f)) station for NTD (first column), TD (second column), and ITD (third column). Lines indicate the mean wind direction and numbers on top of the lines are mean values of that particular direction. Colors indicate particular wind speed ranges as indicated by the legend.

\subsubsection{Hail}

According to Changnon [41], hail swaths usually occur near the lightning center. In the majority of cases, they occur sidewise (left or right) to lightning centers but can also occur along the line or at some angle. Although the author did not comment on average or maximal displacements between the lightning center and hail swaths, using the figures and data he provided, it could be concluded that the general distance from lightning centers does not exceed $20 \mathrm{~km}$. Wapler [23] analyzed the life cycles of hailstorms using lightning radar and rotation characteristics. She found that on average, there was a slight displacement of storm centers toward the northeast with respect to hail strikes and that a $15 \mathrm{~km}$ radius held most lightning activity. A positive TSII index, in the first approximation, could be related to lightning centers presented by the two aforementioned authors; thus, we should expect that recorded hail swaths occur with some spatial distance. First, the spatial distribution of hail cases recorded by the station is shown in Figure 6a, which reveals a high spatial variability in hail frequency (indicated with circle size and color). Additionally, the higher values of hail are obtained near the mountains and hills, suggesting orographically induced hail. Furthermore, with a greater $15 \mathrm{~km}$ area of influence, 185 hail records were associated with ITD environments, while an additional 58 of them were associated with TD environments (Figure 6b). More detailed analysis was performed to inspect the impact 
of different areas of influence. Figure $6 \mathrm{c}$ displays that $28 \%$ of hail records contained the TSII footprint directly above the station, another $29 \%$ in close proximity, while the rest of the events decreased significantly with greater distance, as shown in Figure 6c. These results are in good agreement with Changnon [41]. Out of 84 cases that were not associated with ITD (Figure 6b), 58 fell in the period of low thunderstorm activity (October to April). Considering NTD hail and the values of the TD and ITD environments, we can conclude that almost all hail in the northeastern Adriatic is produced by thunderstorms, while during the low thunderstorm activity season, hail tends to occur without the presence of a TSII footprint. In terms of skill score, it is difficult to make conclusive comments due to the very high number of false alarms. Hail occurs relatively rarely when considering station measurements (up to 2.8 times a year in Istria) and usually covers very small areas; thus, the direct connection between the TSII and hail is not possible without radar estimates. However, it is reassuring to note that the TSII performs several times better in terms of false alarm ratio compared with lightning-only data, as it narrows thunderstorm size to only intense areas. Additionally, preliminary studies have suggested that some hail reports are associated with thunderstorms producing multiple TSIIs, as suggested in Figure 2.

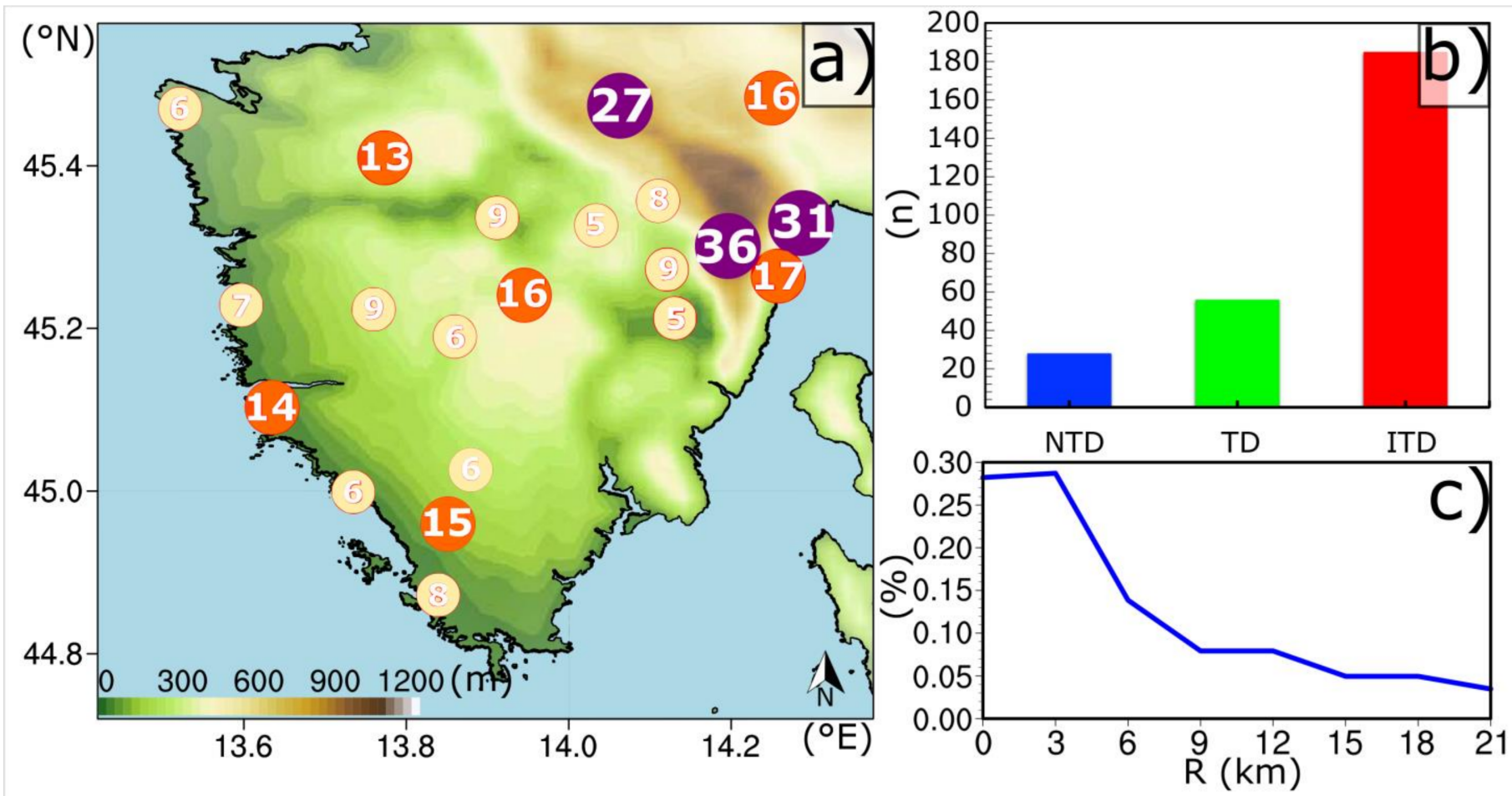

Figure 6. (a) Spatial distribution of the hail cases per station for the observed period (2008-2017). Circle sizes and color indicate hail frequencies $<1$ hail day per year (small, yellow), hail frequencies $<2$ hail days per year (medium, orange) and hail frequencies $>2$ hail days per year (large, purple). Color bar shading indicates elevation (m). (b) Distribution of hail cases with respect to different thunderstorm environments using a $15 \mathrm{~km}$-area of influence. (c) Percentage of thunderstorm hail as a function of distance from the ITD environment.

\subsubsection{Waterspouts}

Most waterspout reports come from the west coast of Istria (Figure 7a, Supplementary Table S1), and their occurrence varies annually (Figure 7b). Reports are also concentrated around more populated areas, which increases the chance of waterspout detection. According to Figure 7c, there were 15 days classified as fair weather (NTD environment) in an 11-year period. This is a rather small number if we take into account that approximately half of the waterspouts observed in the Adriatic fall into this category [10]. Since the exact time is not available for some events and it can be assumed that the same synoptic environment caused waterspout developments on a particular day, the final number of 
27 days with lightning is extracted, of which 20 days had the ITD environment included. The selection was performed by using a $15 \mathrm{~km}$ area of influence to compensate for the lack of accuracy of the reports. Half of the reports connected to ITD were events with two or more waterspouts, and the highest number, at least 11 waterspouts, was observed on the 28 August 2013, the largest documented waterspout outbreak in the Adriatic Sea [42,43]. Only 3 days (events) that are associated with the TSII are observed in the low thunderstorm activity period. Although it is difficult to establish a direct connection between TSII and waterspout occurrence, it is evident that in this dataset, a large number $(20 / 27)$ of waterspouts were associated with the TSII. There is room for further research that can be conducted for larger areas and longer datasets, together with the help of a radar network along the coast that will be available in the near future with the strategic project "Modernisation of the National Weather Observation Network in Croatia-METMONIC" [44].

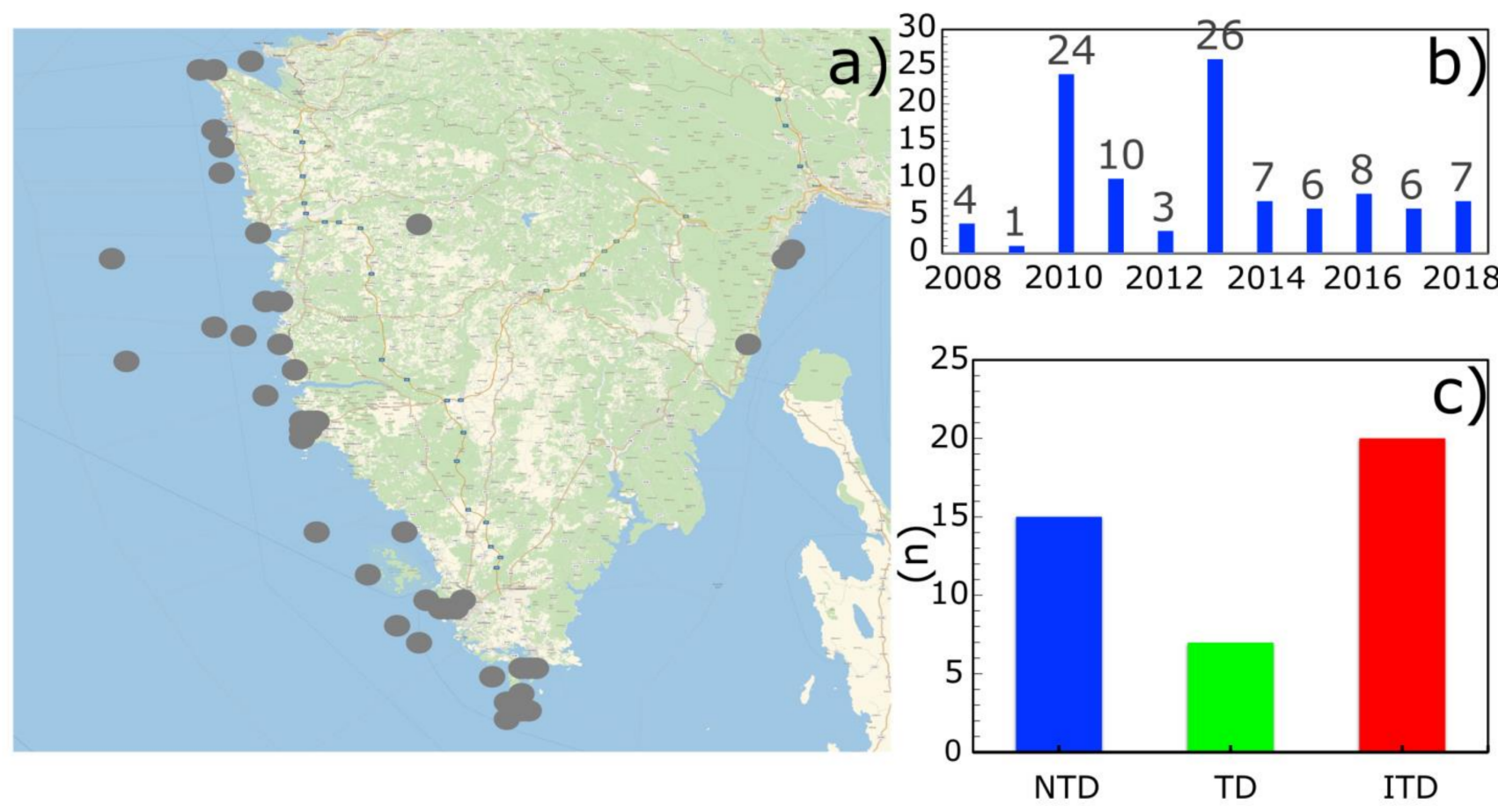

Figure 7. (a) A spatial distribution of all available waterspouts and events recorded in the observed period (2008 to 2018) for the northeastern Adriatic region. (b) Yearly reporting activity of waterspout. (c) Distribution of waterspout days with respect to different thunderstorm environments using a $15 \mathrm{~km}$-influence area.

Most waterspouts in the Adriatic are non-mesocyclonic according to Renko et al., [10], and approximately half of them occur without the presence of lightning, but still, some of them can produce damage at a level of F2 or greater on the Fujita scale [44]. At this moment, we can speculate that the TSII could be a good predictor for stronger tornadoes ( $\geq$ F/EF2), as originally defined by Hales [45], that develop mostly from mesocyclones, since the lightning flash rate and mesocyclone behavior trend similarly, possibly as a result of the common factor of the updraft [46].

\subsubsection{Instability Indices}

In addition to ground measurements and observations, we calculated deep-layer shear (DLS) and various instability indices-most unstable CAPE (MUCAPE, J/kg), lifted index $\left(\mathrm{LI},{ }^{\circ} \mathrm{C}\right)$, and $\mathrm{K}$-index $\left(\mathrm{KI},{ }^{\circ} \mathrm{C}\right)$ - to inspect the difference between NTD, TD, and ITD environmental days. The results of these parameters are shown in Figure 8, with the distributions for the NTD, TD, and ITD environments displayed in blue, green, and red, respectively. Although our observation period is relatively short (11 years) compared with the observed period from Jelić et al., the results of instability indices for non-hail days 
do correspond well with currently obtained NTD days. As expected, TD days do have a more unstable atmosphere, which is confirmed with green box-whiskers (Figure 8a-c). Compared with both NTD and TD days, a day with ITD exhibits even more instability, which is shown with a red box-whisker. In the case of MUCAPE, the median value on thunderstorm days is $652[\mathrm{~J} / \mathrm{kg}]$, while that on ITD is $832[\mathrm{~J} / \mathrm{kg}]$. These high results for ITD days correspond well with other reports for severe thunderstorm environments in Europe, such as that by Púčik et al. [2]. Similar results were obtained for KI and LI, while DLS remained similar throughout all events, and equivalent results were obtained for $3 \mathrm{~km}$ shear and $1 \mathrm{~km}$ shear (not shown). One possible reason for this could be that daily mean fields oversmoothed the DLS signal, rendering it insensitive for comparison. The other reason could be that the northeastern Adriatic region is poorly represented in ERA5 due to highly complex topography, which is not procurable by ERA5 resolution. Nevertheless, the obtained results indicate that days with a TSII footprint mostly highlight very unstable environments capable of producing potentially severe weather followed by high intensity of rain, hail, waterspouts, and wind gusts.
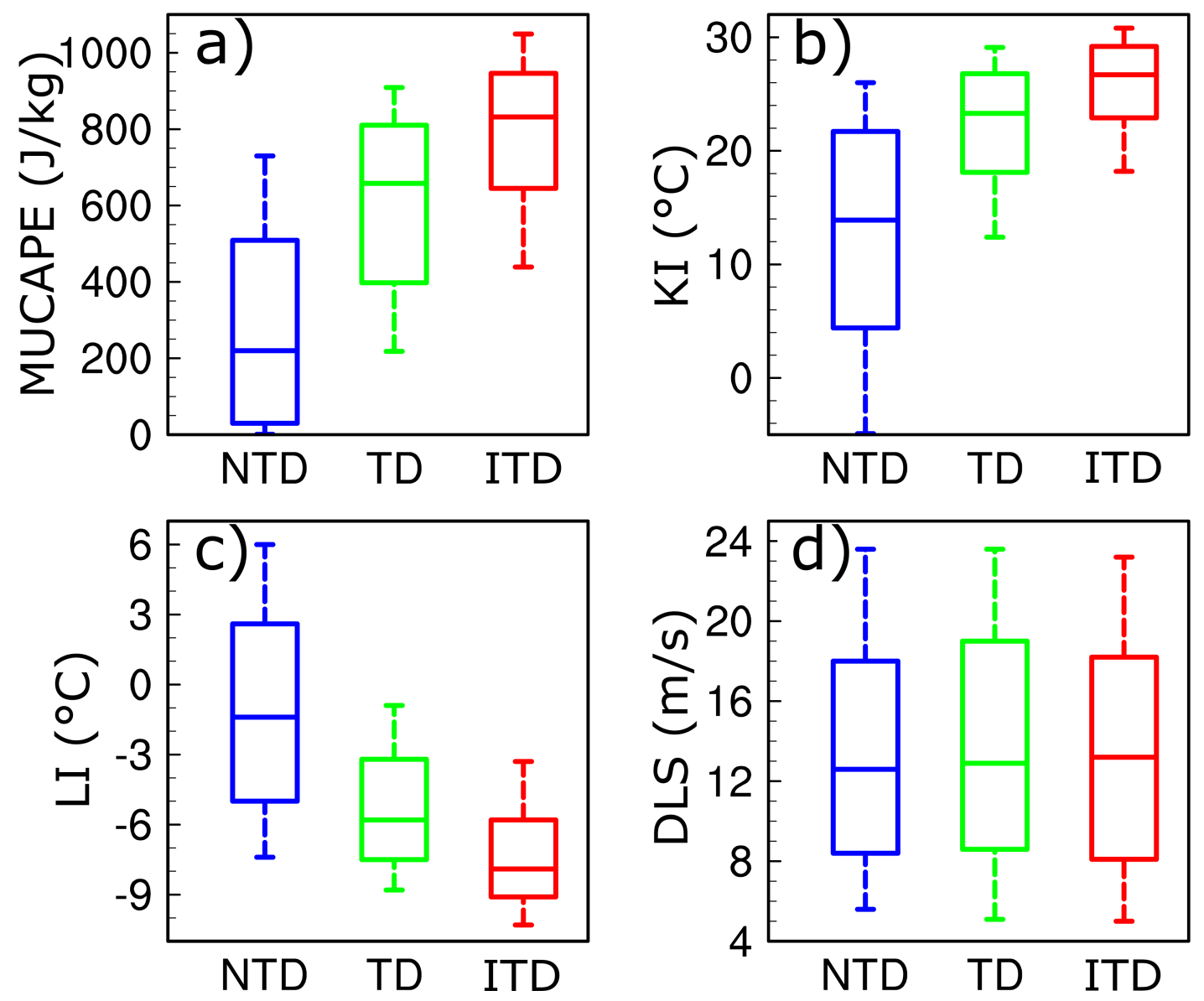

Figure 8. Box and whisker plot comparisons of the instability indices on NTD (blue), TD (green), and ITD days (red) with the (a) most unstable CAPE (MUCAPE, J/kg), (b) K-index $\left({ }^{\circ} \mathrm{C}\right),(\mathbf{c})$ lifted index at $500 \mathrm{hPa}\left({ }^{\circ} \mathrm{C}\right)$, and (d) deep-layer shear (DLS, $\mathrm{m} / \mathrm{s}$ ) in the lowermost $6 \mathrm{~km}$. The median values are shown by the horizontal lines in the boxes; box edges are the 25 th and 75th percentiles, and the whiskers represent the 10th and 90th percentiles.

\subsubsection{Local Thunderstorms}

Local thunderstorms are usually short-lived and less accurately reported/observed in radar and satellite data [45-49]. Local thunderstorm impact is very localized both in space and time; therefore, in comparison with MCSs or larger systems, it is often rendered insignificant and usually neglected or ignored as part of thunderstorm research. However, local thunderstorms can still be very intense and produce some severe effects. A 
considerable lack of techniques to efficiently capture environments that can lead to severe effects caused by local thunderstorms can be traced back to the difficulties associated with high resolution modeling of local phenomena and associated verification, as well as an overall lack of understanding of these processes.

To provide this new angle, which is often missing, and to contribute to a better understanding of local thunderstorms, we attempted to isolate only intense local thunderstorms such as single-cell $\mathrm{Cb}$. As selection criteria, we only used those days where the size of the TSII footprint did not exceed $90 \mathrm{~km}^{2}$. This corresponds to 10 pixels of our grid $(3 \mathrm{~km} \times 3 \mathrm{~km})$, which is approximately $11 \%$ of our domain. This selection is far from perfect since in one day, we can have several isolated intense local thunderstorms cumulatively exceeding the 10-pixel criteria. However, these criteria allow us to examine atmospheric environments, which lead to these localized occurrences. The aim is to inspect how successful our approach is by using precipitation data, as it represents the largest database at our disposal and provides the best chance to measure possible effects. Since local thunderstorms are hard to capture with station measurements, and to minimize errors, TSII and station data were directly compared, i.e., without the use of the area of influence.

During 364 days with intense local thunderstorms, 79 records of rain were directly associated with ITD. Furthermore, there were 1081 records of rain connected with TD and 7168 records of NTD environments. The comparison of these results is presented in Figure 9, presenting NTD, TD, and ITD events, respectively. The results show that thunderstorms can be intense regardless of their size. Moreover, the TSII footprint highlights the most intense storm regions leading to high precipitation intensities and rain rates regardless of thunderstorm size. Even for days including the smallest possible TSII footprint (only one pixel with positive TSII $(3 \mathrm{~km} \times 3 \mathrm{~km})$ ), we obtain similar results (not shown). Additionally, within the area of influence, 11 hail records were associated with the TSII, and the largest distance between the TSII footprint and hail record was $9 \mathrm{~km}$. There were 11 events with strong wind at the inland station and five events at the coastal station using the $15 \mathrm{~km}$ area of influence. Based on our data, waterspouts related to the TSII tended to occur within large systems, as we were able to relate only one event to an intense local thunderstorm.

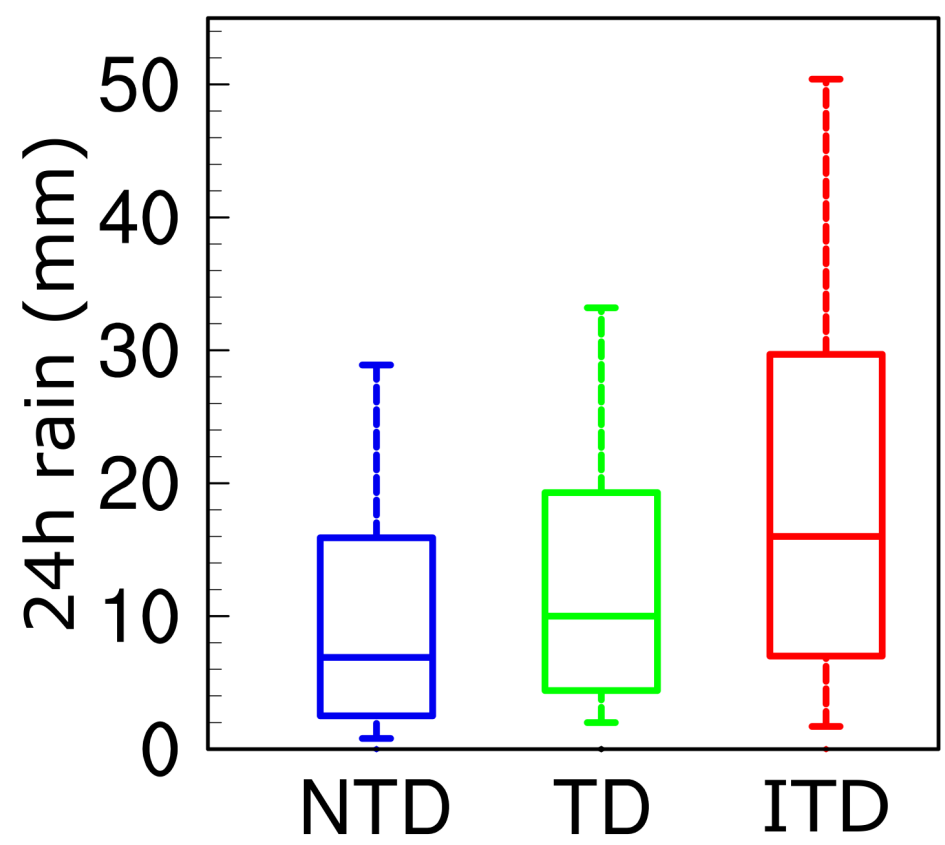

Figure 9. Box and whisker plots of daily precipitation totals (mm) for NTD (blue), TD (green), and ITD (red) environments. Plots are based on 364 intense local thunderstorm days over the 37 precipitation stations shown in Figure 1b. 
Moreover, the same inspection is performed for instability indices, and the results are shown in Figure 10, where 109 days have shown with only one TSII pixel (ITD 1 ), 364 days with up to 10 TSII pixels $\left(\right.$ ITD $_{10}$ ) and, as in Figure 6, all days with any number of TSII pixels (ITD), respectively. It is surprising to note how small the difference between particular thunderstorms is. Intense local thunderstorms (ITD ${ }_{1}$ and ITD $\left.\mathrm{ID}_{10}\right)$ do have slightly less unstable environments for all indices and a slightly more sheared environment in the case of only one TSII pixel. However, all values of instability indices confirmed more unstable environments compared with TD environments, as shown in Figure 6. These results suggest that very unstable environments tend to produce intense thunderstorms regardless of their size and archetype (single cell, multicell and supercell).
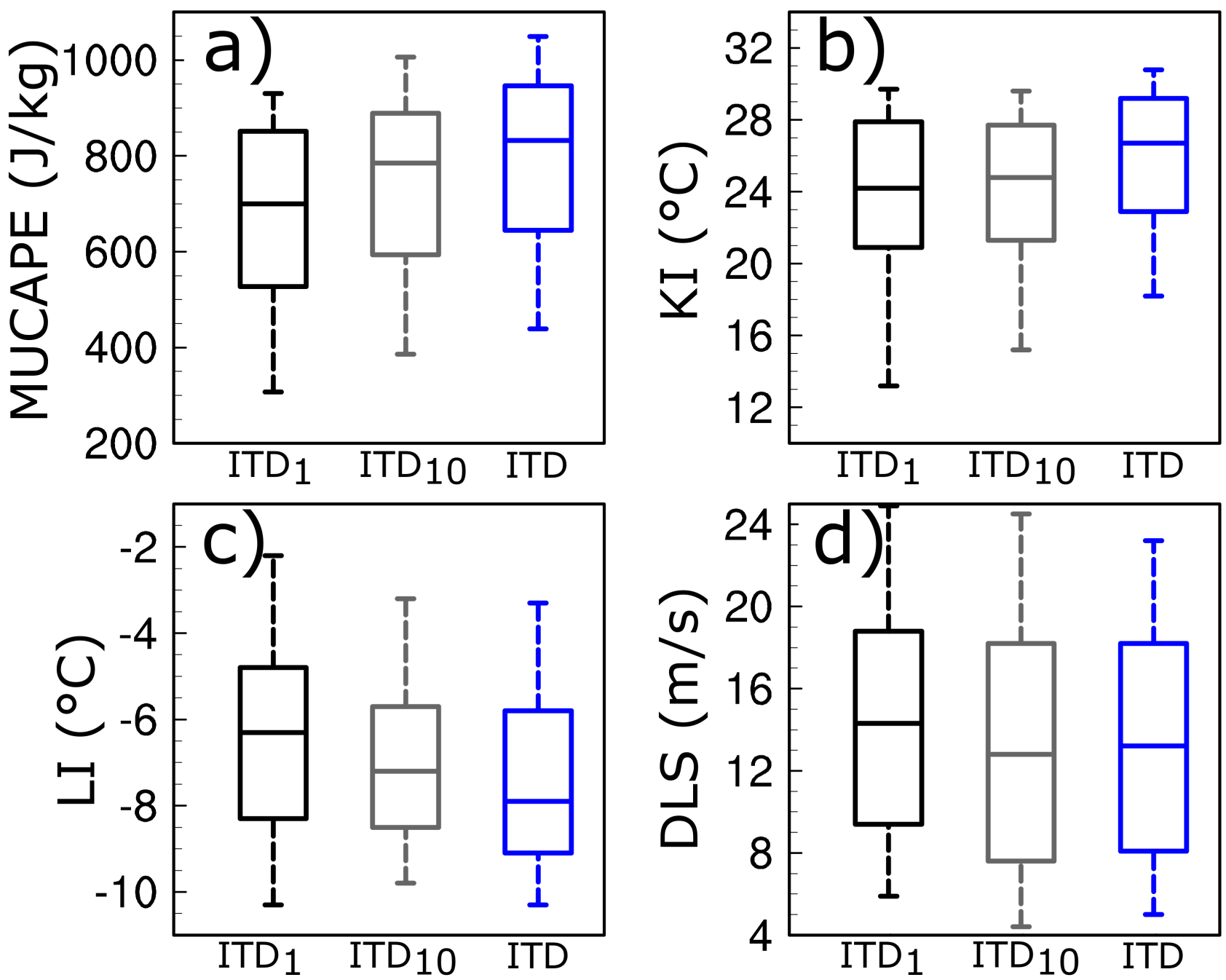

Figure 10. Box and whisker plot comparisons of the (a) most unstable CAPE (MUCAPE, J/kg), (b) K-index $\left({ }^{\circ} \mathrm{C}\right)$, (c) lifted index at $500 \mathrm{hPa}\left({ }^{\circ} \mathrm{C}\right)$, and (d) deep-layer shear (DLS, $\mathrm{m} / \mathrm{s}$ ) in the lowermost $6 \mathrm{~km}$ for a different size of the TSII footprint on one day. The black box and whisker show 109 days with a footprint of only one TSII pixel (ITD 1$), 364$ days with a footprint of up to 10 TSII pixels (ITD 10 ) and 740 days with a footprint of any number of pixels (ITD).

\subsubsection{Summary of the Verification}

In summary, the TSII introduces the added value in thunderstorm analysis, as summarized in Table 1. There is a strong relationship between TSII footprint and both precipitation intensities and daily amounts. Winds within the ITD tend to be stronger, while both hail and waterspouts prefer the presence of severe thunderstorms as defined by the TSII. Approximately $76 \%$ of thunderstorm hail is related to ITD environments. The same thunderstorms are related to the most unstable environments through the MUCAPE, KI and LI indices 
regardless of their size; the values obtained for $\mathrm{ITD}_{10}$ are similar to those obtained by the ITD. Since we know both the time and location of the TSII index, for the first time, we are able to provide both spatial and temporal information of potentially severe effects, which can be very useful information for damage claims, identification of hazardous regions for policy making and analysis of the temporal dynamics of the phenomena.

Table 1. Summary table of median values of precipitation, wind, and instability indices as well as number of cases of hail and waterspouts sorted through three observed environments. Additionally, if available, data from intense local thunderstorms $\left(\mathrm{ITD}_{10}\right)$ are provided for comparison with ' $\mathrm{X}$ ' denoting unavailable data.

\begin{tabular}{|c|c|c|c|c|c|c|c|c|c|}
\hline & \multirow{2}{*}{$\begin{array}{l}\text { Rain Intensity } \\
(\mathrm{mm} / \mathrm{min})\end{array}$} & \multirow{2}{*}{$\begin{array}{l}\text { Daily Precipitation } \\
\text { (mm/Day) }\end{array}$} & \multicolumn{2}{|c|}{ Wind (m/s) } & \multirow{2}{*}{$\begin{array}{c}\text { Hail } \\
\text { (Number) }\end{array}$} & \multirow{2}{*}{$\begin{array}{l}\text { Waterspouts } \\
\text { (Number) }\end{array}$} & \multicolumn{3}{|c|}{ Instability Indices } \\
\hline & & & Coast & Inland & & & (CAPE J/kg) & $\mathrm{KI}\left({ }^{\circ} \mathrm{C}\right)$ & LI $\left({ }^{\circ} \mathrm{C}\right)$ \\
\hline NTD & 0.06 & 4.7 & 9.1 & 7.4 & 28 & 15 & 220 & 13.9 & -1.4 \\
\hline TD & 0.18 & 9.8 & 12.1 & 8.8 & 56 & 6 & 658 & 23.3 & -5.8 \\
\hline ITD & 0.46 & 17.6 & 14.9 & 10.2 & 185 & 20 & 832 & 26.8 & -7.9 \\
\hline $\mathrm{ITD}_{10}$ & $x$ & 15.2 & $X$ & $X$ & $X$ & $X$ & 785 & 24.8 & -7.2 \\
\hline
\end{tabular}

\subsection{Climatology}

We developed the TSII as a new index for the identification of the occurrence of intense thunderstorms and the identification of the area over which the storm had the strongest impact. Based on 11 years of lightning data, we can examine both the spatial and temporal activity of intense thunderstorms, and as a contribution to local-scale research, we include our findings regarding 364 days over which we identified intense local thunderstorms. We also provide potential synoptic drivers behind the NTD, TD, ITD and ITD $_{10}$ environmental days.

\subsubsection{Spatial Characteristics}

In Figure 11, the spatial characteristics of total thunderstorm days, TSII and intense local thunderstorm days are presented. All maps show annual mean frequencies. The results obtained for thunderstorm days (Figure 11a) are consistent with the results shown in Galanaki et al. [50] for the period from 2005 to 2014. However, our results provide more structure due to higher resolution, and therefore, the overall number of thunderstorm days is lower. Nevertheless, contrary to thunderstorm days, the TSII (Figure 11b) indicates regions that are more likely to be affected by severe weather. A comparison of thunderstorm days with TSII days (Figure 11a,b) reveals that, while the northeastern region of the study area experiences a significant number of thunderstorm days, only a few of those days feature severe weather. In addition, portions of the northwestern region and southern half of the study region experienced fewer thunderstorm days than other areas, but a larger fraction of them were severe. Intense local thunderstorms (Figure 11c) also have preferred regions of occurrence, as indicated by higher numbers on the map. Precipitation could be directly compared with the TSII, as we have shown that the point under the TSII produces the highest intensities and rain rates (Figures 2 and 7). Furthermore, the particular location and neighboring points up to $12 \mathrm{~km}$ have a higher likelihood of hail, which is supported by long-term hail climatology for Istria presented by Jelić et al. [27] (their Figure 6) and by Strzinar and Skok [51] (their Figure 8), who used radar assessments for the warm part of the year to investigate hail. Strong winds related to thunderstorms will occur more frequently inland, although greater speeds can occur along the west coast, as suggested by the coastal station shown in Section 3.2. Based on our results, it seems that the eastern part of the sea is more affected by thunderstorms and, thus, is more likely to produce intense phenomena, including waterspouts. Most TSII days in that region are related to larger thunderstorms. Unfortunately, that region is scarcely populated and has only two rain gauge stations; therefore, we cannot confirm our results for this region without extra observations and reports. 

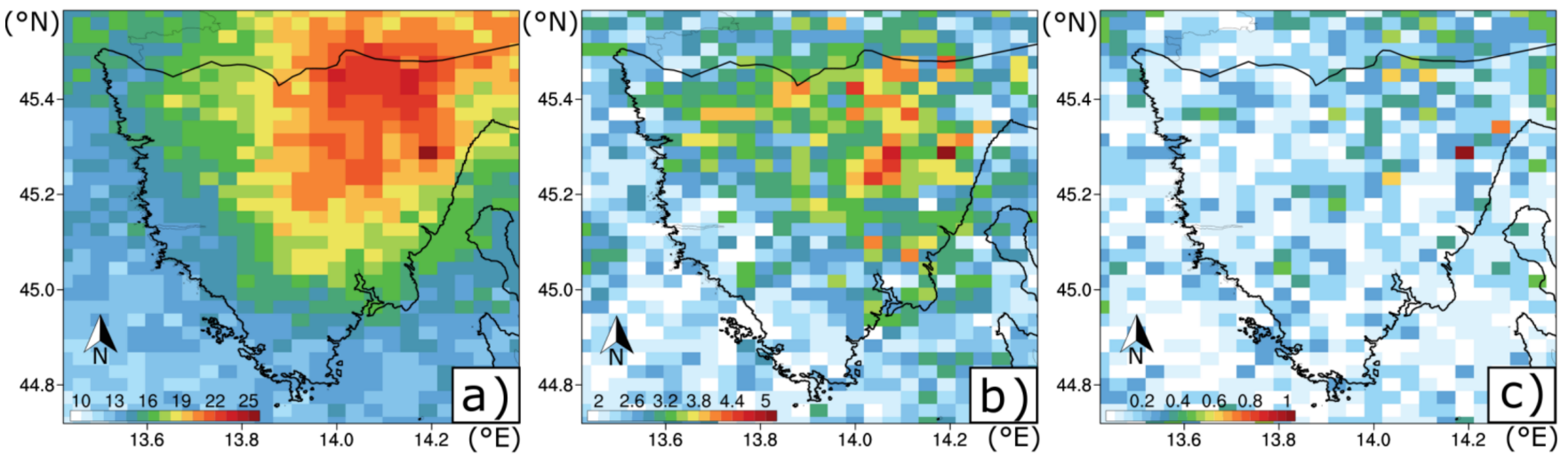

Figure 11. Spatial distribution of annual mean (a) thunderstorm days, (b) TSII days and (c) intense local thunderstorm days based on 11 years (2008-2018) of lightning data.

\subsubsection{Temporal Characteristics}

On average, there were 247 NTD days and 118 thunderstorm days in a given year. Of the 118 thunderstorm days, 51 had TD and 67 had ITD environments. Intense local thunderstorm $\left(\mathrm{ITD}_{10}\right)$ days tend to occur 33 times on average during the year. Interannual variations in total thunderstorm days, TD days, ITD and ITD 10 days are shown in Figure 12a, revealing moderate variation from the least active year in 2015 to the most active in 2018. While TD had a maximum in 2009, the $\mathrm{ITD}_{10}$ environments do not show any pronounced increases or decreases throughout the years. Furthermore, we examined a share of ITD $_{10}$ within all ITD days (not shown) and found that on average, there were approximately $50 \%$ intense local thunderstorm days with approximately $10 \%$ variation. The years 2014 and 2016 had the lowest intense local thunderstorm activities, 36\% and $38 \%$, respectively. These years were characterized by the Croatian Meteorological and Hydrological Service as very wet to extremely wet. In contrast, the years 2008 and 2013 had relatively high percentages of intense local thunderstorm activity $(60 \%)$, and Croatian Meteorological and Hydrological Service reports categorized those years as average to wet. However, no conclusive statements could be made due to various numbers of ITDs, thunderstorm days, and sub-seasonal factors, which are not specifically considered here.
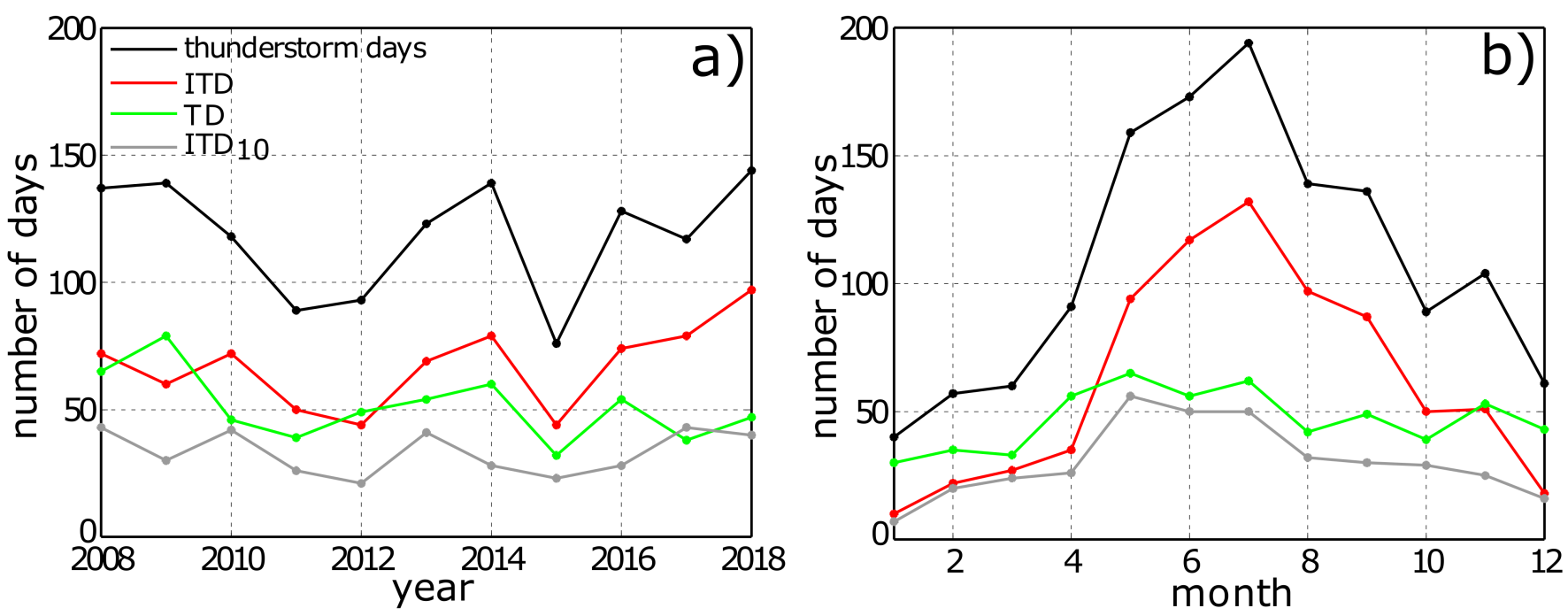

Figure 12. Temporal decomposition of thunderstorm days (black), TD days (green), ITD days (red) and ITD 10 (gray) for (a) interannual, and (b) annual distributions. 
The annual distribution in terms of monthly mean values shown in Figure $12 \mathrm{~b}$ revealed that ITD environments have the strongest activity during the warmer part of the year, increasing in May, which is in agreement with other studies on lightning activity [26,52,53]. The overall maxima on both total thunderstorm days and ITD are in July, with a gradual decline by December. ITD $_{10}$ has a similar pattern, although it peaks immediately in May and continues to gradually decrease by the end of the year with still pronounced activity in June and July. TD environmental days have a more irregular shape, and they start increasing one month earlier (April) and peak in May; however, they tend to remain active throughout the rest of the year. An interesting result is a slight increase in November for TD days and ITD days. As previously reported for heavy precipitation in the northeastern Italy [52], waterspouts over the Adriatic Sea [10], and hail over Istria [27], November stands out as a month with a relatively high amount of thunderstorm activity over a wider northeastern Adriatic region (e.g., [37]). Additionally, the same signature was obtained through lightning cases from the EUCLID network for western and central Europe [54]. However, this could not be seen for intense local thunderstorm days.

\subsubsection{Weather Types}

Synoptic drivers were present in most days during the observed period, with $49 \%$ of all days exposed to cyclonic activity, $42 \%$ to anticyclonic activity and the remaining $9 \%$ of all days reported as a quasi-non-gradient day. The results for the entire period of WTs obtained in this study (2008-2018) correspond well with a previous study by Jelić et al. [27]. Therefore, Figure 8 (WT distribution over the analyzed period) and Figure 9 (composite of surface pressure and $700 \mathrm{hPa}$ winds) in their study can be used as references. Here, Figure 13 shows the distribution of particular WTs for NTD, TD, ITD days and ITD $_{10}$ environmental days. NTD days are likely to occur in any WT, although they tend toward anticyclonic and quasi-non-gradient environments in $60 \%$ of days. TD days and ITD and ITD $_{10}$ days have fairly similar distributions, showing clear dominance of cyclonic and quasi-non-gradient environments with $75 \%, 84 \%$ and $82 \%$ of the days, respectively. Most anticyclonic thunderstorms and ITD environments are related to WT8, representing the back side of deep (red) and shallow (blue) systems, which is similar to findings reported in Jelić et al. [27] for hail days (their Figures $8 b$ and 9 for air flow regimes). For WT8 and WT5, air flow comes from the NW and NE directions, which may advect colder air masses and produce unstable environments that are favored by thunderstorms. By examining the share of the ITD $_{10}$ (Figure 13d) in total ITD (Figure 13c) per WT (not shown), we noticed that $\mathrm{ITD}_{10}$ slightly prefers shallow systems, probably due to weaker winds allowing local convection to develop.

High similarity in WT drivers between intense local thunderstorms and larger scale intense thunderstorms, and equivalent similarities with respect to instability indices between the aforementioned scales, offer equal likelihood for particular environmental combinations to generate both larger-scale and local thunderstorms; however, intense effects will occur regardless. Thus, our results suggest that using only model data, one can highlight strong and unstable environments, as has already been done [54,55], but one will not acquire information about final storm size and areas affected by thunderstorms. 

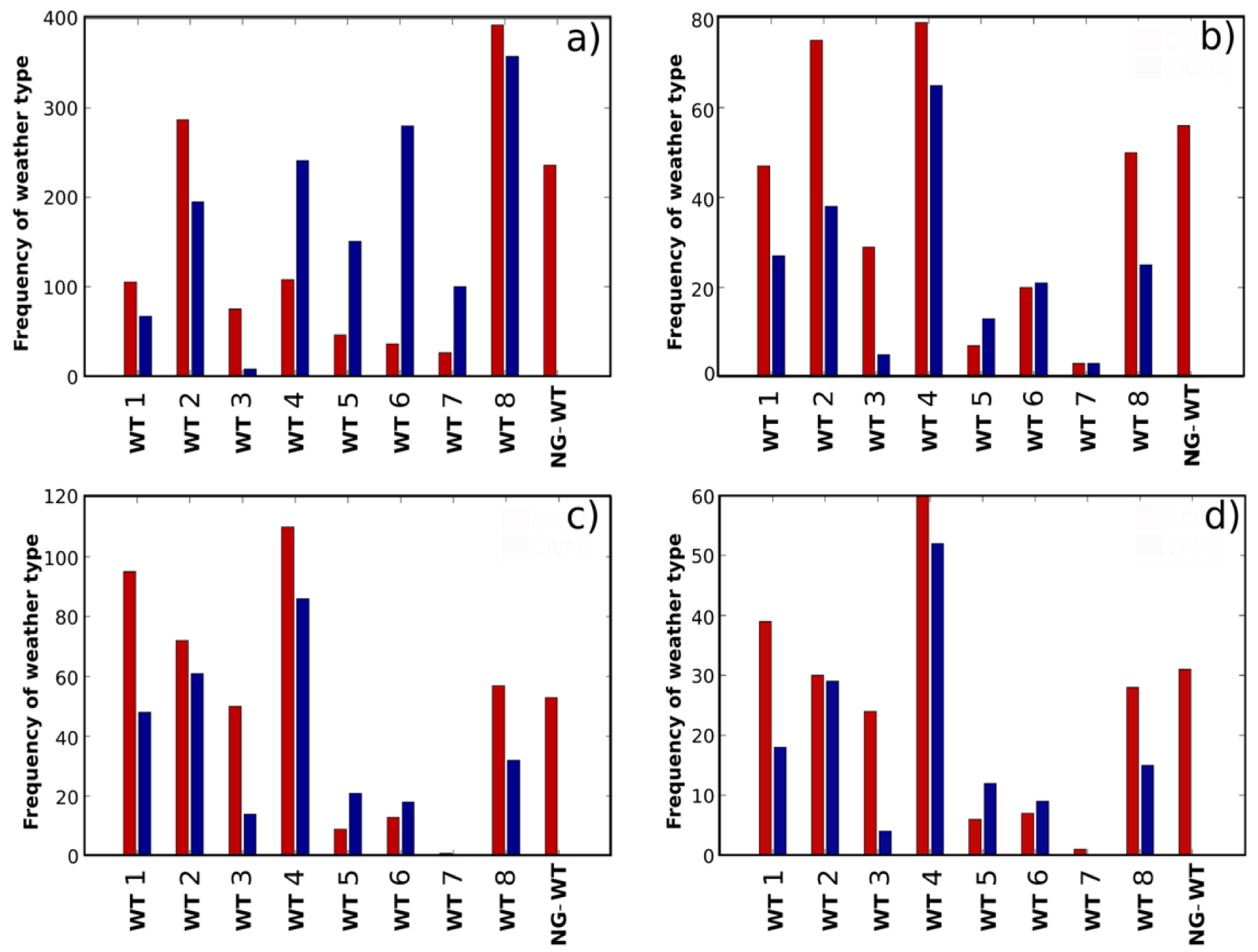

Figure 13. Weather-type (WT) classifications obtained from the objective algorithm using ERA5 reanalysis data (2008-2018) for (a) NTD days, (b) TD days, (c) ITD days and (d) ITD 10 days. In all subfigures, the red bars denote deep systems, and the blue bars denote shallow systems. WT1, WT2, WT3, and WT4 represent the front, top, back and lower sides of cyclones, respectively, while WT5-8 represent the same respective sides of anticyclonic systems. NG-WT presents a quasi-non-gradient pressure field.

\subsection{Future Development and Potential of the TSII}

Through the presented work, we established a robust and efficient Eulerian method for the identification of potentially severe storms using the TSII, which is well suited for climatological purposes and offers reasonable diagnostic potential. However, based on our obtained knowledge, we believe the potential of the TSII far exceeds the presented work. Although we used physically or empirically established thresholds, such as a minimum of 4.5 lightning strikes to filter unphysical TSIIs and $2 \sigma$ as a detection criteria, both values can be iterated to tailor the method for a particular severe effect. If, for instance, the TSII breaches $3 \sigma$ or more, then this can suggest very strong intensification (as seen in Figure $2 \mathrm{~b}$ if we compare the first and second TSII) and potentially hold additional value. By introducing the measure $\alpha \sigma$, where $\alpha$ is factor of the breach, the TSII can become a nonbinary index showing the strength of intensification, as shown previously for a lightning jump calculation [20]. Furthermore, multiple TSIIs from a single storm can also be detected, as shown in Figure 2b. We noticed in multiple cases that hail tends to occur more often near these locations, but detailed investigation was beyond the scope of this paper. Although the focus was on diagnostics and climatology, we expect that TSII has a predictive skill 
similar to lightning jump(s). If one would establish live retrieval of lightning data and a computation algorithm based on the presented method, the first few TSII values would indicate the beginning of thunderstorm intensification. The shape and size of both the TSII and lightning footprint could indicate the current size and intensity of the storm, while each new timestep would suggest the thunderstorm trajectory and dynamics. However, for these purposes, we believe one should consider the strength of the intensification $(\alpha \sigma)$ rather than a predefined binary value. A similar method, but for lightning jump calculation, was introduced by Farnell et al. [24,25], where the authors used a $1 \mathrm{~km} \times 1 \mathrm{~km}$ raster for lightning retrieval and then defined a larger cell by grouping all pixels with more than one flash together. Furthermore, they applied a computational algorithm using the $2 \sigma$ threshold and inspected the lead time between the first lightning jump and most hail occurrences. Their results, however, showed that some events exhibited lightning jumps after a severe effect was observed. In addition, other studies reported the same phenomenon [23]. We speculate that by using the Eulerian approach, these events can, to some extent, be nullified. However, to date, no inspection has been conducted to test this hypothesis.

In model development, a potentially useful direction would be to find the relationship between the recently developed lightning potential index (LPI) [56] and TSII, and use it as an indicator for impacted areas, e.g., the size of thunderstorms. Additionally, HAILCAST, as a time-dependent hail growth model [57], is a relatively new tool for hail prediction, which is mostly coupled with the numerical model WRF [58]. Although its verification should mainly be performed through ground measurements and radar proxies, the TSII would significantly aid in filling gaps for regions not covered with other more established data sources.

\section{Conclusions}

The development of a new TSII based on lightning data, inspection utilizing multiple data sources (precipitation, wind, hail, waterspouts and ERA5) and the capability of the new index using dominant synoptic drivers is presented. The main conclusions are presented as follows:

I. The newly developed TSII represents a tool for thunderstorm monitoring from the Eulerian standpoint, allowing the detection of areas over which thunderstorms experience rapid increases in lightning activity. Since lightning data currently provide several times higher spatial and temporal resolution (compared with radar and satellite imaging) with large spatial coverage, calculation of the TSII allows a new perspective for thunderstorm investigations on larger scales.

II. Through our verification process (Table 1), we showed that regions of thunderstorms exhibiting positive TSII values reported considerably greater precipitation maximum intensities and significantly higher accumulated $24 \mathrm{~h}$ values. In addition, thunderstorms exhibiting a TSII footprint tend to produce stronger wind gusts while, over the coast, larger thunderstorms have the potential to generate waterspouts. Hail is shown to be closely related to thunderstorms with over $90 \%$ coincidence, and $77 \%$ of that hail is related to thunderstorms exhibiting a TSII footprint.

III. The method for TSII derivation is independent of storm size, allowing for the identification of even the smallest intense thunderstorms. These storms also reported equivalently large precipitation values at points where the TSII was positive. Additionally, these thunderstorms were related to strong gusts and hail occurrence. Thus, intense local thunderstorms should be taken into consideration in future research as potentially hazardous. In contrast, only one waterspout event was associated with an intense local thunderstorm.

IV. Inspection of instability indices (Table 1) on thunderstorm days revealed that the days with a TSII clearly have the most unstable environments, reporting a median MUCAPE of $832 \mathrm{~J} / \mathrm{kg}$. Although MUCAPE is considerably high on TD days 
(652 [J/ kg]), days containing one pixel with a positive TSII still have higher median values, as shown in Figure 8a. Similar results were obtained for the KI and LI.

V. Spatial analysis revealed a clear difference between thunderstorm days and areas affected by intense thunderstorm activity. This suggests that thunderstorm days, as a variable, should only be used as a first guess for determining regions with hazardous weather, while the TSII footprint will reveal those areas with considerably higher confidence. Temporal analysis revealed that intense thunderstorms tend to initiate later in the warm season (May), peak in June and decline toward December, while intense local thunderstorms mostly prefer the period from May to July. Nevertheless, both types are detectable throughout the year, which is in agreement with previous studies on lightning [50], hail [27], and waterspouts [10]. VI. Synoptic drivers responsible for the formation of thunderstorm environments revealed no apparent difference between TD, ITD and ITD $_{10}$ days. Combining these results with instability indices, it was shown by reanalysis proxy data that the likelihood of intense and potentially hazardous environments is the same for both local and large-scale thunderstorms.

VII. The TSII can be used as a diagnostic variable for climatological studies to ascertain exposure to intense thunderstorm environments, which is useful for riskassessment maps for insurance companies or policy makers, general estimation of areas not covered with more established meteorological data sources, or to obtain local temporal dynamics. Additionally, it can be used operationally to identify areas currently experiencing severe weather, especially local thunderstorms. Moreover, it can be used as a tool for validation and partial verification of modeled information regarding lightning (i.e., lightning potential index) and hail. The calculation of the TSII for severe storms tends to produce multiple positive values, providing continuous insight into storm activity and representing a basis for further research.

Supplementary Materials: The following are available online at https: / www.mdpi.com/article / 10.3390/atmos12070908/s1, Table S1: A list of all available waterspouts and events recorded in the observed period.

Author Contributions: Conceptualization, D.J. and M.T.P.; methodology, D.J. and B.M.; software, D.J., B.M., A.B.V. and O.A.M.; validation, D.J., A.B.V. and T.R.; formal analysis, D.J. and B.M.; investigation, D.J. and A.B.V.; resources, D.J., B.M., O.A.M. and T.R.; data curation, D.J.; writing-original draft preparation, D.J.; writing-review and editing, M.T.P., A.B.V. and T.R.; visualization, D.J., O.A.M. and A.B.V.; supervision, M.T.P.; project administration, M.T.P.; funding acquisition, M.T.P. All authors have read and agreed to the published version of the manuscript.

Funding: This research and APC was funded by SWALDRIC (IZHRZO-180587), which is financed through the Croatian-Swiss Research Program of the Croatian Science Foundation, and the Swiss National Science Foundation, with funds obtained from the Swiss-Croatian Cooperation Programme.

Institutional Review Board Statement: Not applicable.

Informed Consent Statement: Not applicable.

Data Availability Statement: Data for this research were obtained from three sources. Lightning data were obtained from the Lightning Detection Network in Europe (LINET) (https: / www.nowcast. de/en/solutions/linet-data; 11 June 2021) (Betz et al., 2009a). ERA5 data are available online ( https:/ / www.ecmwf.int/en/forecasts/datasets/reanalysis-datasets/era5; 11 June 2021.) (Copernicus Climate Change Service, 2017). The precipitation, wind, hail, and waterspout data can be available through inquiries through the following links (https:/ / meteo.hr/proizvodi_e.php?section= proizvodi_usluge\&param=services; 11 June 2021), since the data used fall under the data policy of the Croatian Meteorological and Hydrological Service; for more information, please contact the following email address (usluge@cirus.dhz.hr).

Acknowledgments: We thank the Croatian Meteorological and Hydrological Service for providing us with precipitation, wind, hail and waterspout data, and we thank ECMWF for providing access 
to ERA5 data. Special thanks are extended to the UBIMET group and their data support center for rapid replies and quality support. We acknowledge the Croatian-Swiss Research Program of the Croatian Science Foundation, and the Swiss National Science Foundation, with funds obtained from the Swiss-Croatian Cooperation Programme for supporting this research.

Conflicts of Interest: The authors declare no conflict of interest.

\section{References}

1. Hoeppe, P. Trends in Weather Related Disasters-Consequences for Insurers and Society. Weather Clim. Extrem. 2016, 11, 70-79. [CrossRef]

2. Púčik, T.; Groenemeijer, P.; Rýva, D.; Kolář, M. Proximity Soundings of Severe and Nonsevere Thunderstorms in Central Europe. Mon. Weather Rev. 2015, 143, 4805-4821. [CrossRef]

3. Púčik, T.; Castellano, C.; Groenemeijer, P.; Kühne, T.; Rädler, A.T.; Antonescu, B.; Faust, E. Large Hail Incidence and Its Economic and Societal Impacts across Europe. Mon. Weather Rev. 2019, 147, 3901-3916. [CrossRef]

4. Changnon, S.; Changnon, D.; Hilberg, S. Hailstorms Across the Nation: An Atlas about Hail and Its Damages; Contract Reports; Illinois State Water Survey: Champaign, IL, USA, 2009; Volume 101.

5. Gaál, L.; Molnar, P.; Szolgay, J. Selection of Intense Rainfall Events Based on Intensity Thresholds and Lightning Data in Switzerland. Hydrol. Earth Syst. Sci. 2014, 18, 1561-1573. [CrossRef]

6. Cipolla, G.; Francipane, A.; Noto, L.V. Classification of Extreme Rainfall for a Mediterranean Region by Means of Atmospheric Circulation Patterns and Reanalysis Data. Water Resour Manag. 2020, 34, 3219-3235. [CrossRef]

7. Klingle, D.L.; Smith, D.R.; Wolfson, M.M. Gust Front Characteristics as Detected by Doppler Radar. Mon. Weather Rev. 1987, 115, 905-918. [CrossRef]

8. Mohr, S.; Kunz, M.; Richter, A.; Ruck, B. Statistical Characteristics of Convective Wind Gusts in Germany. Nat. Hazards Earth Syst. Sci. 2017, 17, 957-969. [CrossRef]

9. Edwards, R.; LaDue, J.G.; Ferree, J.T.; Scharfenberg, K.; Maier, C.; Coulbourne, W.L. Tornado Intensity Estimation: Past, Present, and Future. Bull. Am. Meteorol. Soc. 2013, 94, 641-653. [CrossRef]

10. Renko, T.; Kuzmić, J.; Šoljan, V.; Mahović, N.S. Waterspouts in the Eastern Adriatic from 2001 to 2013. Nat. Hazards 2016, 82, 441-470. [CrossRef]

11. Punge, H.J.; Kunz, M. Hail Observations and Hailstorm Characteristics in Europe: A Review. Atmos. Res. 2016, 176-177, 159-184. [CrossRef]

12. Punge, H.J.; Bedka, K.M.; Kunz, M.; Werner, A. A New Physically Based Stochastic Event Catalog for Hail in Europe. Nat. Hazards 2014, 73, 1625-1645. [CrossRef]

13. Ávila, E.E.; Bürgesser, R.E.; Castellano, N.E.; Collier, A.B.; Compagnucci, R.H.; Hughes, A.R.W. Correlations between Deep Convection and Lightning Activity on a Global Scale. J. Atmos. Sol. Terr. Phys. 2010, 72, 1114-1121. [CrossRef]

14. Takahashi, T. Riming Electrification as a Charge Generation Mechanism in Thunderstorms. J. Atmos. Sci. 1978, 35, 1536-1548. [CrossRef]

15. Betz, H.D.; Schumann, U.; Laroche, P. (Eds.) Lightning: Principles, Instruments and Applications: Review of Modern Lightning Research; Springer: Dortrecht, The Netherlands, 2009; ISBN 978-1-4020-9078-3.

16. Mazzetti, T.O.; Fuelberg, H.E. An Analysis of Total Lightning Flash Rates Over Florida. J. Geophys. Res. Atmos. 2017, 122. [CrossRef]

17. Hayward, L.; Whitworth, M.; Pepin, N.; Dorling, S. Review Article: A Comprehensive Review of Datasets and Methodologies Employed to Produce Thunderstorm Climatologies. Nat. Hazards Earth Syst. Sci. 2020, 20, 2463-2482. [CrossRef]

18. Schultz, C.J.; Petersen, W.A.; Carey, L.D. Preliminary Development and Evaluation of Lightning Jump Algorithms for the Real-Time Detection of Severe Weather. J. Appl. Meteorol. Climatol. 2009, 48, 2543-2563. [CrossRef]

19. Gatlin, P.N.; Goodman, S.J. A Total Lightning Trending Algorithm to Identify Severe Thunderstorms. J. Atmos. Ocean. Technol. 2010, 27, 3-22. [CrossRef]

20. Chronis, T.; Carey, L.D.; Schultz, C.J.; Schultz, E.V.; Calhoun, K.M.; Goodman, S.J. Exploring Lightning Jump Characteristics. Weather Forecast. 2015, 30, 23-37. [CrossRef]

21. Schultz, C.J.; Petersen, W.A.; Carey, L.D. Lightning and Severe Weather: A Comparison between Total and Cloud-to-Ground Lightning Trends. Weather Forecast. 2011, 26, 12. [CrossRef]

22. Pineda, N.; Bech, J.; Rigo, T.; Montanyà, J. A Mediterranean Nocturnal Heavy Rainfall and Tornadic Event. Part II: Total Lightning Analysis. Atmos. Res. 2011, 100, 638-648. [CrossRef]

23. Wapler, K. The Life-Cycle of Hailstorms: Lightning, Radar Reflectivity and Rotation Characteristics. Atmos. Res. 2017, 193, 60-72. [CrossRef]

24. Farnell, C.; Rigo, T.; Pineda, N. Lightning Jump as a Nowcast Predictor: Application to Severe Weather Events in Catalonia. Atmos. Res. 2017, 183, 130-141. [CrossRef]

25. Farnell, C.; Rigo, T.; Pineda, N. Exploring Radar and Lightning Variables Associated with the Lightning Jump. Can We Predict the Size of the Hail? Atmos. Res. 2018, 202, 175-186. [CrossRef]

26. Mikuš, P.; Telišman Prtenjak, M.; Strelec Mahović, N. Analysis of the Convective Activity and Its Synoptic Background over Croatia. Atmos. Res. 2012, 104-105, 139-153. [CrossRef] 
27. Jelić, D.; Megyeri, O.A.; Malečić, B.; Belušić Vozila, A.; Strelec Mahović, N.; Telišman Prtenjak, M. Hail Climatology Along the Northeastern Adriatic. J. Geophys. Res. Atmos. 2020, 125. [CrossRef]

28. Betz, H.D.; Schmidt, K.; Laroche, P.; Blanchet, P.; Oettinger, W.P.; Defer, E.; Dziewit, Z.; Konarski, J. LINET-An International Lightning Detection Network in Europe. Atmos. Res. 2009, 91, 564-573. [CrossRef]

29. Hersbach, H.; Bell, B.; Berrisford, P.; Hirahara, S.; Horányi, A.; Muñoz-Sabater, J.; Nicolas, J.; Peubey, C.; Radu, R.; Schepers, D.; et al. The ERA5 Global Reanalysis. Q. J. R. Meteorol. Soc. 2020, 146, 1999-2049. [CrossRef]

30. Mikuš Jurković, P.; Mahović, N.S.; Počakal, D. Lightning, Overshooting Top and Hail Characteristics for Strong Convective Storms in Central Europe. Atmos. Res. 2015, 161-162, 153-168. [CrossRef]

31. Franc, B.; Uglešić, I.; Piliškić, S. Lightning Data Utilization in Power System Control. J. Energy 2015, 64, 62-77.

32. Stipetić, N.; Franc, B.; Uglešić, I.; Mesić, M.; Ivanković, I. Improving Lightning Location System and Advance Control, Maintenance and Planning of Transmission Power System Using Lightning Location System Data. In Proceedings of the International Colloquium on Lightning and Power Systems, Ljubljana, Slovenia, 18 September 2017.

33. Uglešić, I.; Franc, B.; Stipetić, N. Lightning Stroke Measurements, Data Verification and Application in Power Systems. In Proceedings of the VI Russian Conference on Lightning Protection (RCLP), Saint Petersburg, Russia, 17 April 2018.

34. Blumberg, W.G.; Halbert, K.T.; Supinie, T.A.; Marsh, P.T.; Thompson, R.L.; Hart, J.A. SHARPpy: An Open-Source Sounding Analysis Toolkit for the Atmospheric Sciences. Bull. Am. Meteorol. Soc. 2017, 98, 1625-1636. [CrossRef]

35. Belušić Vozila, A. Wind Characteristics in the Present and Future Climate Obtained from Regional Climate Models' Simulations over Broader Adriatic Region. Ph.D. Thesis, University of Zagreb Faculty of Science (Department of Geophysics), Zagreb, Croatia, 2018.

36. Grisogono, B.; Belušić, D. A Review of Recent Advances in Understanding the Meso- and Microscale Properties of the Severe Bora Wind. Tellus A 2009, 61, 1-16. [CrossRef]

37. Belušić, A.; Prtenjak, M.T.; Güttler, I.; Ban, N.; Leutwyler, D.; Schär, C. Near-Surface Wind Variability over the Broader Adriatic Region: Insights from an Ensemble of Regional Climate Models. Clim. Dyn. 2018, 50, 4455-4480. [CrossRef]

38. Horvath, K.; Lin, Y.-L.; Ivančan-Picek, B. Classification of Cyclone Tracks over the Apennines and the Adriatic Sea. Mon. Weather Rev. 2008, 136, 2210-2227. [CrossRef]

39. Ivančan-Picek, B.; Glasnović, D.; Jurčec, V. Analysis and Aladin Prediction of a Heavy Precipitation Event on the Eastern Side of the Alps during Map IOP 5. metz 2003, 12, 103-112. [CrossRef]

40. Toreti, A.; Giannakaki, P.; Martius, O. Precipitation Extremes in the Mediterranean Region and Associated Upper-Level SynopticScale Flow Structures. Clim. Dyn. 2016, 47, 1925-1941. [CrossRef]

41. Changnon, S.A. Temporal and Spatial Relations between Hail and Lightning. J. Appl. Meteorol. Climatol. 1992, 31, 587-604. [CrossRef]

42. Sioutas, M.V.; Renko, T.; Szilagyi, W.; Keul, A.G. Waterspout Climatology over the Central-Eastern Mediterranean. In Proceedings of the COMECAP 2014; 12 International Conference of Meteorology, Climatology and Atmospheric Physics, Heraklion, Crete, Greece, 28-31 May 2014; Volume 3, pp. 154-158.

43. Renko, T.; Ivušić, S.; Telišman Prtenjak, M.; Šoljan, V.; Horvat, I. Waterspout Forecasting Method Over the Eastern Adriatic Using a High-Resolution Numerical Weather Model. Pure Appl. Geophys. 2018, 175, 3759-3778. [CrossRef]

44. Projekt Modernizacije Meteorološke Motriteljske Mreže u RH. Available online: https:/ / meteo.hr/istrazivanje/METMONICbrosura.pdf (accessed on 11 June 2021).

45. Browning, K.A.; Blyth, A.M.; Clark, P.A.; Corsmeier, U.; Morcrette, C.J.; Agnew, J.L.; Ballard, S.P.; Bamber, D.; Barthlott, C.; Bennett, L.J.; et al. The Convective Storm Initiation Project. Bull. Am. Meteorol. Soc. 2007, 88, 1939-1956. [CrossRef]

46. Poljak, G.; Prtenjak, M.T.; Kvakić, M.; Strelec Mahović, N.; Babić, K. Wind Patterns Associated with the Development of Daytime Thunderstorms over Istria. Ann. Geophys. 2014, 32, 401-420. [CrossRef]

47. Mecikalski, J.R.; Rosenfeld, D.; Manzato, A. Evaluation of Geostationary Satellite Observations and the Development of a 1-2 h Prediction Model for Future Storm Intensity: Forecasting Storm Intensity. J. Geophys. Res. Atmos. 2016, 121, 6374-6392. [CrossRef]

48. Kehler-Poljak, G.; Telišman Prtenjak, M.; Kvakić, M.; Šariri, K.; Večenaj, Ž. Interaction of Sea Breeze and Deep Convection over the Northeastern Adriatic Coast: An Analysis of Sensitivity Experiments Using a High-Resolution Mesoscale Model. Pure Appl. Geophys. 2017, 174, 4197-4224. [CrossRef]

49. Li, H.; Cui, X.; Zhang, D.-L. On the Initiation of an Isolated Heavy-Rain-Producing Storm near the Central Urban Area of Beijing Metropolitan Region. Mon. Weather Rev. 2017, 145, 181-197. [CrossRef]

50. Galanaki, E.; Lagouvardos, K.; Kotroni, V.; Flaounas, E.; Argiriou, A. Thunderstorm Climatology in the Mediterranean Using Cloud-to-Ground Lightning Observations. Atmos. Res. 2018, 207, 136-144. [CrossRef]

51. Stržinar, G.; Skok, G. Comparison and Optimization of Radar-Based Hail Detection Algorithms in Slovenia. Atmos. Res. 2018, 203, 275-285. [CrossRef]

52. Manzato, A.; Cicogna, A.; Pucillo, A. 6-Hour Maximum Rain in Friuli Venezia Giulia: Climatology and ECMWF-Based Forecasts. Atmos. Res. 2016, 169, 465-484. [CrossRef]

53. Púčik, T.; Groenemeijer, P.; Rädler, A.T.; Tijssen, L.; Nikulin, G.; Prein, A.F.; van Meijgaard, E.; Fealy, R.; Jacob, D.; Teichmann, C. Future Changes in European Severe Convection Environments in a Regional Climate Model Ensemble. J. Clim. 2017, 30, 6771-6794. [CrossRef] 
54. Rädler, A.T.; Groenemeijer, P.H.; Faust, E.; Sausen, R.; Púčik, T. Frequency of Severe Thunderstorms across Europe Expected to Increase in the 21st Century Due to Rising Instability. NPJ Clim. Atmos. Sci. 2019, 2, 30. [CrossRef]

55. Taszarek, M.; Brooks, H.E.; Czernecki, B.; Szuster, P.; Fortuniak, K. Climatological Aspects of Convective Parameters over Europe: A Comparison of ERA-Interim and Sounding Data. J. Clim. 2018, 31, 4281-4308. [CrossRef]

56. Yair, Y.; Lynn, B.; Price, C.; Kotroni, V.; Lagouvardos, K.; Morin, E.; Mugnai, A.; del Carmen Llasat, M. Predicting the Potential for Lightning Activity in Mediterranean Storms Based on the Weather Research and Forecasting (WRF) Model Dynamic and Microphysical Fields. J. Geophys. Res. 2010, 115, D04205. [CrossRef]

57. Brimelow, J.C.; Reuter, G.W.; Poolman, E.R. Modeling Maximum Hail Size in Alberta Thunderstorms. Weather Forecast. 2002, 17, 15. [CrossRef]

58. Adams-Selin, R.D.; Ziegler, C.L. Forecasting Hail Using a One-Dimensional Hail Growth Model within WRF. Mon. Weather Rev. 2016, 144, 4919-4939. [CrossRef] 